\title{
Influences of semantic and syntactic context on open- and closed-class words
}

\author{
CYMA VAN PETTEN and MARTA KUTAS \\ University of California, San Diego, La Jolla, California
}

\begin{abstract}
Event-related potentials (ERPs) were recorded as subjects read semantically meaningful, syntactically legal but nonsensical and random word strings. The constraints imposed by formal sentence structure alone did not reduce the amplitude of the $\mathrm{N} 400$ component elicited by open-class words, whereas semantic constraints did. Semantic constraints also eliminated the word-frequency effect of a larger $\mathrm{N} 400$ for low-frequency words. Responses to closed-class words exhibited reduced N400 amplitudes in syntactic and congruent sentences, indicating that formal sentence structure placed greater restrictions on closed-class words than it did on open-class words. However, unlike the open-class results, the impact of sentence context on closed-class words was stable across word positions, suggesting that these syntactic constraints were applied only locally. A second ERP component, distinct from the N400, was elicited primarily by congruent closed-class words.
\end{abstract}

Much experimental effort has been devoted to demonstrating that people are faster at identifying (or require less sensory information to identify) words that occur in an informative context than they are at identifying words that do not. In natural discourse, readers and listeners have several theoretically distinct sources of information that they may use in the transformation of a visual or acoustic signal into a meaningful representation. These include associations between individual words in long-term memory, semantic information derived from larger chunks of the ongoing discourse or real-world knowledge, syntactic restrictions provided by the grammar of the language, the overall probability of occurrence of particular words based on their frequency of usage in the reader's/listener's experience with the language, and pragmatic cues. Psycholinguistic research has attempted to describe how each source of information is used, addressing such questions as whether different cues are utilized serially or in parallel, whether they are allowed to interact or are kept distinct until a relatively late stage of processing, whether each type of information is applied to all words or only a subset, and whether or not different sources of information or vocabulary types are interpreted by distinct neural circuits.

In the present experiment, we examined the impact of three potentially informative cues for the processing of

\footnotetext{
A brief report of this study was presented at the 28 th annual meeting of the Society for Psychophysiological Research, in October 1988. We are grateful to Jon Hansen for software support, to Jeff Elman, Liz Bates, Robert Proctor, and two anonymous reviewers for commenting on an earlier version of the paper, to Cathy Harris for helpful discussions, and to Steve Hillyard for making his facilities available for preparation of the manuscript. The work was supported by NSF Grant BNS83-09243 and NICHD Grant HD 22614. C. Van Petten was supported by an NSF graduate fellowship. M. Kutas was supported by Research Career Development Award MH 00322 from NIH. Correspondence should be addressed to Cyma Van Petten, Department of Psychology, University of Arizona, Tucson, AZ 85721.
}

words in sentences: semantic context, syntactic context, and word frequency. In the analysis of contextual influences, open- and closed-class words were considered separately; the effect of frequency was evaluated only for open-class words. Our dependent measure was the eventrelated brain potential (ERP) recorded as subjects read visually presented words. This physiological measure allows the possibility of detecting qualitative differences in the ways in which people use different sources of information to process individual words and the extent to which these may differ for the processing of open- and closedclass words.

The ERP, formed by averaging time segments of the electroencephalogram following similar stimuli, is typically decomposed into "components" based on the differential responsiveness of particular epochs of the waveform to different experimental manipulations. The first $150 \mathrm{msec}$ (approximately) of the ERP response is primarily determined by the sensory characteristics of a stimulus (e.g., size, luminance, loudness, pitch, etc.), although selective attention can enhance these early components (for recent reviews, see Hillyard, Woldorff, Mangun, \& Hansen, 1987; Mangun \& Hillyard, 1990). In contrast, later components of the ERPs are sensitive to a broader range of cognitive activities (for reviews, see Hillyard \& Kutas, 1983; Hillyard \& Picton, 1987; Johnson, 1988; Kutas, 1988; Kutas \& Van Petten, 1988). It is important to note, however, that variations in the amplitude or latency of different ERP components have been linked to different cognitive processes. The possibility thus exists of finding qualitatively distinct ERP signatures of semantic versus syntactic processing or of open-versus closed-class word recognition.

In the analysis of the present data, we will devote particular attention to the N400 component of the ERP, because it has already proved responsive to manipulations of linguistic variables. Most of our knowledge of the fac- 
tors governing $\mathrm{N} 400$ activity concerns semantic constraints in the processing of individual words, presented visually (as printed words or American Sign Language) or aurally (e.g., see Kutas, Neville, \& Holcomb, 1987; Kutas \& Van Petten, 1988; Neville, 1985; Neville, in press). Relatively little research has assessed the sensitivity of the N400 to syntactic constraints. The demonstration of a brain response that is differentially sensitive to semantic and syntactic factors could lend supporting data from the normal population to an idea that has been prominent in the aphasia literature: specialized neural systems subserve semantic and syntactic analyses (e.g., Jakobson, 1956; Zurif, 1980).

The evidence that the $\mathrm{N} 400$ is sensitive to semantic variables has come from two basic paradigms. The first consists of substituting a semantically anomalous word into an otherwise coherent sentence or text and observing an increase in the amplitude of this potential relative to congruent control words (for visual modality, see Kutas \& Hillyard, 1980a, 1980b, 1980c; for auditory modality, see Holcomb, 1985; Karniski, Vanderploeg, Diehl, \& Lease, 1988; McCallum, Farmer, \& Pocock, 1984; Neville, 1985). The second consists of increasing the degree of semantic context relevant to a congruous word and observing a decrease in $\mathrm{N} 400$ amplitude. This paradigm, when applied to the final words of visually presented sentences, yielded an inverse correlation between cloze probability and N400 amplitude of up to $94 \%$ (Kutas \& Hillyard, 1984; Kutas, Lindamood, \& Hillyard, 1984).

With regard to the relationship between the $\mathrm{N} 400$ and syntactic constraints, only the first type of paradigm with anomalous words has been used thus far. Kutas and Hillyard (1983) included morphosyntactic errors in simple texts that also contained semantically anomalous words in order to compare the ERPs with the two types of violations. The morphosyntactic errors were chosen so as to disrupt the meaning of the text as little as possible. They consisted of violations of (1) noun number (e.g., "The leopard uses its long tails to help it keep its balance."), (2) verb tense (e.g., "This allows them to stayed under water for a longer period."), and (3) verb number (e.g., "When cats is climbing or fighting they put out their claws."'). The noun-number and verb-tense violations were comprised of open-class words, whereas the verbnumber violations were equally split between open- and closed-class words. Each of the classes of morphosyntactic violation resulted in some late negative ERP activity. However, these negativities were smaller and more variable across subjects than were the responses to semantically anomalous words. In addition, they tended to have a more anterior distribution across the scalp.

Note, however, that the morphosyntactic violations consisted primarily of errors in word-boundary morphemes; in most cases, the root was the same as the correct word. These syntactic violations were thus inherently weaker than the semantic manipulation, which involved substituting a wholly different word for the original one (e.g., "The cougar can leap from great measles and bound across the ground.'). Overall, we consider the results of this experiment inconclusive and believe that the issue of the N400's sensitivity to syntactic constraints remains unresolved.

In the present experiment, we have applied the second type of paradigm using variations in degree of context to this issue. Rather than attempting to violate a syntactic rule without disrupting the meaning of a sentence, we retained the syntactic structure of sentences, while stripping away much of their semantic coherence. ERP responses to sentences with only a syntactic structure will be compared with normal sentences (both semantic and syntactic structures) and with random word strings. If the N400 is sensitive to syntactic constraints, its amplitude should be reduced in the syntactic sentences relative to the random-word-order, or random, sentences.

While the major contextual variable in the present experiment is type of sentence, the effect of context can also be examined within a given sentence type by comparing words that occur early and late in the string. In previous experiments using only normal sentences, we have observed a decrement in $\mathrm{N} 400$ amplitude with ordinal word position and interpreted this as a reflection of the buildup of contextual constraints across the course of a sentence (Kutas, Van Petten, \& Besson, 1988; Van Petten \& Kutas, 1990a). If this interpretation is correct, then we expect no such amplitude decrement in the random condition.

For syntactic sentences, we have no strong prediction. In pioneering work with materials similar to those used here, Marslen-Wilson and Tyler (1980) observed a decrease in word-monitoring reaction times across syntactic sentences. These results suggested that syntactic context is incremental across the course of a sentence, with each new word adding a degree of constraint for subsequent words. One would have to postulate that listeners build a hierarchical phrase-structure representation on line in order to accommodate such a finding.

More recently, Tyler and Warren (1987) have questioned this original interpretation. They evaluated the benefits of both local and global syntactic structure and the costs of disruptions at either level. Local syntactic context was manipulated by placing targets for word monitoring at the ends of well- or ill-formed phrases (i.e., an article-adjective-noun sequence such as "a slow kitchen" versus an adjective-adverb-noun sequence such as "slow very kitchen"). The impact of global structure was evaluated by placing such phrases either early or late in multiphrase sentences. The other phrases, however, could be combined so as to create an acceptable or unacceptable overall sentence structure. For example, both "The maid/ was carefully peeling/ the potatoes/ in the garden/ because during the summer ..." and "An orange dream/ was loudly watching/ the house/ during smelly nights/ because within these signs ..." are syntactically acceptable sentence fragments, although one is semantically coherent while the other is anomalous. Reordering the original phrases results in unacceptable global structures. These manipulations indicated that word-monitoring times were 
influenced by local phrase structure but not by global syntactic structure. Other manipulations in the Tyler and Warren study (1987), however, suggested that global prosodic structure across an entire utterance could influence the response time to individual words. These results thus indicate that the word-position effect seen for syntactic sentences in an earlier work (Marslen-Wilson \& Tyler, 1980) was due to the presence of normal prosodic, rather than syntactic, structure.

In the present experiment, we present all stimuli visually; phonological and prosodic structure will not be relevant factors. Local constraints would yield an overall difference between syntactically structured and unstructured word strings, but no incremental effects over the course of a sentence. We may thus find that there will be no word position effect within syntactic sentences, even if the $\mathrm{N} 400$ is generally sensitive to syntactic constraint.

The present data set also allows comparisons of the effects of semantic and syntactic context on open- versus closed-class words (i.e., content vs. function). It has been argued that these two lexical classes are accessed differently and that the specialized access device for the closed class is insensitive to meaning because it is in the service of a sentence parser that is concerned solely with assigning phrase structure (Bradley \& Garrett, 1983; Bradley, Garrett, \& Zurif, 1980; Friederici \& Schoenle, 1980; Garrett, 1978; Marin, Saffran, \& Schwartz, 1976). Differential sensitivities to the present experimental manipulations would lend support to the idea that fundamentally different processing mechanisms are engaged by the two lexical classes. In particular, if different cell populations are responsible for the processing of open- and closed-class words, we would expect to see different ERP components or different distributions of components across the scalp elicited by open- and closed-class words.

Kutas and Hillyard (1983) first reported that open- and closed-class words in sentence contexts did indeed elicit different ERPs. This has proved to be a very robust and replicable finding (see Kutas \& Van Petten, 1988; Kutas, Van Petten, \& Besson, 1988). However, the difference between the lexical classes appears to involve variation in more than one ERP component. For example, openclass words elicit much larger N400s than do closed-class words. In addition, the closed-class words elicit a prolonged (200- to more than 700-msec poststimulus) negativity over the anterior part of the head. In the absence of experimental dissociation, it is difficult to determine whether or not this prolonged negativity should be considered a single process or one that is specific to closed-class words. Neville has suggested that the earlier portion (peaking around $300 \mathrm{msec}$ poststimulus), by virtue of its lateral asymmetry (left larger than right), is a distinct component and that it is most pronounced for closed-class words (Neville, in press; Neville, Kutas, Chesney, \& Schmidt, 1986; Neville, Kutas, \& Schmidt, 1982). The initial Kutas and Hillyard (1983) report did not attempt to delineate what portions of the open/closed difference could be attributed to grammatical class, as opposed to differences in length, frequency, or contextual constraint. Relatively little attention has since been given to disentangling these variables, with the exception of a study by Garnsey (1985). She found that, for words presented in isolation for lexical decision, there was a residual $\mathrm{N400}$ difference after open- and closed-class words had been equated for length and frequency. In the present experiment, we did not attempt to equate the two classes on these variables. In this paper, however, we will compare the influences of sentence structure on these two lexical classes.

The final goal of the present experiment was to replicate the interaction of word position $x$ frequency reported in Van Petten and Kutas (1990a), wherein we found that low-frequency words elicited larger N400s than did highfrequency words, but only when the low-frequency words occurred near the beginning of a sentence. The measurement of frequency effects in syntactic and random sentences allow a more rigorous test of our hypothesis that frequency effects are reduced by increasing semantic context. Insofar as this is correct, the word-frequency effect should remain the same throughout the syntactic and random sentences.

\section{METHOD}

\section{Subjects}

Thirty-eight young adults (19 men, 19 women) ranging in age from 18 to 30 years were paid for their participation. All were native English speakers with normal or corrected-to-normal vision. Three subjects were left-handed, and the remaining 35 subjects were right handed; 15 of the right-handed subjects had a left-handed relative in their immediate families. Data were collected from 2 additional subjects, but these were lost due to equipment malfunction.

\section{Materials}

Stimulus materials consisted of 100 exemplars each of normal congruent sentences, syntactically well-structured but semantically anomalous sentences, and random word strings with neither syntactic nor semantic structure. The final words of the congruent sentences had a mean cloze probability of 0.88 ; high- and low-frequency final words did not differ on this off-line measure of predictability. No explicit effort was made to include or exclude lexically associated words from the congruent sentences (a comparison between associative and sentence-level context effects has been the topic of an experiment conducted subsequent to the present one; see Van Petten, 1989).

The syntactic sentences were constructed from a separate set of normal sentences by replacing each open-class word by another of the same form class. ${ }^{1}$ Random sentences were constructed from these syntactic sentences by again replacing the open-class words with new ones and then reordering the closed-class words within each sentence. Thus, the same closed-class items were present in the random condition as in the syntactic condition, but they were arranged in a nonmeaningful way.

Each sentence was terminated by a period. Examples of the three sentence types are shown in Table 1 . The mean number of words in each of the three sentence types were: congruent $=9.0$, syntactic $=9.1$, and random $=9.1 ;$ standard deviation was 2.3 words for each.

A target word was selected to follow each sentence. For each sentence type, half of the targets were words that had occurred in the sentence (old) and half were not (new). Both the old and the new targets were evenly divided between open- and closed-class 
Table 1

Examples of the Three Types of Sentence Stimuli

\section{Congruent Sentences}

The tenants were evicted when they did not pay the last two months rent.

It is supposed to bring seven years bad luck to break a mirror. Most new drugs are tested on white lab rats.

He was so wrapped up in the past that he never thought about the present.

Everything she owned was in a brown paper bag.

\section{Syntactic Sentences}

He ran the half white car even though he couldn't name the raise. The necklace pulled the certain cat and borrowed the spoon.

He went out of right food and had to go to the black bed. In the wet levels fathers were smoking by congress.

They married their uranium in store and cigarettes.

Random Sentences

To prided the bury she room she of peanut the had china Into thumb cable male the effort his into group rowboat. She which had jazz anchor a she to straight couldn't gun. Was reason and ash the angry with technician.

Every opened the gripped they stepping kind steel pine.

words. Thus, there were 12 target types ( 3 sentence types $\times 2$ lexical classes $\times$ old $/$ new). Words selected to be old targets were distributed across the full range of sentence positions; this was equated for each of the old-target types.

ERPs elicited by open- and closed-class words in each of the three sentence types were averaged according to ordinal sentence position irrespective of word frequency, excluding the final words. Five categories of sentence position were used for closed-class words: Words 1 and 2, Words 3 and 4, Words 5 and 6, Words 7 and 8 , and Words 9 and 10. A similar scheme was used for open-class words but, because very few sentences began with open-class words, the first category consisted only of second words rather than a sum of first and second words. ${ }^{2}$

Open-class words also were averaged according to a combination of frequency and sentence position. Word frequency was defined as the sum of all regularly inflected forms and categorized as above or below 30 occurrences per million (Francis \& Kučera, 1982). Only three categories of intermediate sentence position were used: the first open-class word of each sentence (usually occurring in the second or third sentence position), Words 3 and 4 (assuming another open-class word preceded them in the sentence), and Words
5 and up, not including the final word. Sentence-final words were analyzed separately. The reduced number of word-position categories was necessary in order to have enough low-frequency words to form a reliable ERP average, while still retaining some information about the fate of the word-frequency effect across the course of a sentence. Table 2 shows mean frequencies, lengths, and numbers of words in each of the word position/frequency categories.

\section{Procedure}

The 300 stimulus sentences were randomly intermixed and presented in sets of 20 . The subject was seated in a comfortable chair in a sound-attentuated chamber facing a CRT controlled by an Apple II microcomputer. The CRT screen was approximately $100 \mathrm{~cm}$ away; at this distance, each letter in a word subtended $0.36^{\circ}$ of visual angle horizontally. Sentences were presented one word at a time in the center of the screen (black on white) for a duration of $200 \mathrm{msec}$. The interword stimulus-onset asynchrony was $600 \mathrm{msec}$. The target word assigned to each sentence followed $1.5 \mathrm{sec}$ after the onset of the final word. The subject was instructed to indicate whether or not the target word had been present in the sentence by pressing one of two buttons held in either hand. Reaction time and accuracy were recorded. Across subjects, the assignment of the left or right hand to represent old or new was counterbalanced. The interval between the presentation of a target and the beginning of the next sentence was $4.5 \mathrm{sec}$. Each subject was given a practice set of 20 trials before the first set and allowed rest periods between sets of sentences as desired.

Procedures for recording and averaging the electroencephalogram were the same as those for Experiment 1 of Van Petten and Kutas (1990a).

\section{Data Analysis}

The N400 component of the ERP was quantified as the mean voltage in a latency range of 300 - to 500 -msec poststimulus relative to a 100 -msec prestimulus baseline. Amplitude measures of other ERP components are detailed in the Results section.

All of the statistical measures to be reported consisted of repeated measures analyses of variance (ANOVAs) with the amplitude or latency measures from each recording site of each subject. ERP effects typically vary in amplitude from one recording site to another; consequently, most of the main effects of condition we report were accompanied by interactions between condition and recording site, as well as main effects of recording site. We have adopted a policy of not reporting this mass of statistics unless the interaction qualifies or elucidates the effects of experimental condition, as in the case of an interaction between site and condition in the absence of

Table 2

Summary Statistics of Sentence Position $\times$ Frequency Categories

\begin{tabular}{|c|c|c|c|c|c|c|c|c|}
\hline & \multicolumn{2}{|c|}{ Unpreceded Words } & \multicolumn{2}{|c|}{ Words 3 and 4} & \multicolumn{2}{|c|}{ Words $5-10$} & \multicolumn{2}{|c|}{ Final Words } \\
\hline & $\begin{array}{c}\text { High } \\
\text { Frequency }\end{array}$ & $\begin{array}{c}\text { Low } \\
\text { Frequency }\end{array}$ & $\begin{array}{c}\text { High } \\
\text { Frequency }\end{array}$ & $\begin{array}{c}\text { Low } \\
\text { Frequency }\end{array}$ & $\begin{array}{c}\text { High } \\
\text { Frequency }\end{array}$ & $\begin{array}{c}\text { Low } \\
\text { Frequency }\end{array}$ & $\begin{array}{c}\text { High } \\
\text { Frequency }\end{array}$ & $\begin{array}{c}\text { Low } \\
\text { Frequency }\end{array}$ \\
\hline \multicolumn{9}{|c|}{ Congruent } \\
\hline $\begin{array}{l}\text { No. of words } \\
\text { Frequency } \\
\text { Length }\end{array}$ & $\begin{array}{c}76 \\
391 \pm 55 \\
5.3 \pm .2\end{array}$ & $\begin{array}{c}24 \\
13 \pm 2 \\
6.5 \pm .3\end{array}$ & $\begin{array}{c}54 \\
376 \pm 61 \\
5.0 \pm .2\end{array}$ & $\begin{array}{c}19 \\
13 \pm 2 \\
6.1 \pm .2\end{array}$ & $\begin{array}{c}138 \\
370 \pm 31 \\
5.0 \pm .1\end{array}$ & $\begin{array}{c}29 \\
13 \pm 2 \\
6.7 \pm .4\end{array}$ & $\begin{array}{c}77 \\
262 \pm 43 \\
4.7 \pm .2\end{array}$ & $\begin{array}{c}23 \\
16 \pm 2 \\
5.3 \pm .3\end{array}$ \\
\hline \multicolumn{9}{|c|}{ Syntactic } \\
\hline $\begin{array}{l}\text { No. of words } \\
\text { Frequency } \\
\text { Length }\end{array}$ & $\begin{array}{c}81 \\
370 \pm 47 \\
5.3 \pm .2\end{array}$ & $\begin{array}{c}19 \\
8 \pm 2 \\
6.2 \pm .5\end{array}$ & $\begin{array}{c}53 \\
329 \pm 51 \\
5.2 \pm .2\end{array}$ & $\begin{array}{c}24 \\
14 \pm 2 \\
5.8 \pm .3\end{array}$ & $\begin{array}{c}144 \\
423 \pm 37 \\
5.0 \pm .1\end{array}$ & $\begin{array}{c}27 \\
12 \pm 2 \\
5.2 \pm .3\end{array}$ & $\begin{array}{c}76 \\
219 \pm 20 \\
5.3 \pm .2\end{array}$ & $\begin{array}{c}24 \\
12 \pm 1 \\
5.2 \pm .3\end{array}$ \\
\hline \multicolumn{9}{|c|}{ Random } \\
\hline $\begin{array}{l}\text { No. of words } \\
\text { Frequency } \\
\text { Length }\end{array}$ & $\begin{array}{c}81 \\
341 \pm 43 \\
5.5 \pm .2\end{array}$ & $\begin{array}{c}19 \\
8 \pm 2 \\
5.5 \pm .4\end{array}$ & $\begin{array}{c}53 \\
358 \pm 56 \\
5.3 \pm .2\end{array}$ & $\begin{array}{c}24 \\
14 \pm 2 \\
5.8 \pm .3 \\
\end{array}$ & $\begin{array}{c}144 \\
437 \pm 37 \\
5.1 \pm .1\end{array}$ & $\begin{array}{c}27 \\
14 \pm 2 \\
5.5 \pm .3 \\
\end{array}$ & $\begin{array}{c}76 \\
230 \pm 22 \\
5.4 \pm .2 \\
\end{array}$ & $\begin{array}{c}24 \\
12 \pm 2 \\
5.6 \pm .4\end{array}$ \\
\hline
\end{tabular}

Note-Frequencies and lengths are shown as means plus or minus standard errors. 
a main effect for condition. In the cases in which condition $\times$ electrode interactions are of interest, we have applied the Huynh-Feldt correction for violations of sphericity (see Vasey \& Thayer, 1987). In these cases, we report the original degrees of freedom, the epsilon correction factor, and the corrected probability level.

\section{RESULTS}

\section{Behavioral Performance}

Reaction times and error rates for the various target types are shown in Table 3. Overall reaction times for correct responses averaged about $1 \mathrm{sec}$. The subjects responded to old targets somewhat more quickly $(36 \mathrm{msec}$ ) but also less accurately (3.8\%) than they did to new targets. There was a large difference between openand closed-class targets; open-class words had an overall advantage in reaction time of $110 \mathrm{msec}$ [main effect of lexical class, $F(1,37)=42.1, p<.0001]$. A three-way interaction between sentence type, lexical class, and old $/$ new $[F(2,74)=7.96, \epsilon=0.98, p<.001]$ proved to be due to the fact that the influence of sentence type was limited to the new closed-class category, with target responses following congruent sentences being faster than those following syntactic sentences $[F(1,37)=24.2$, $p<.001]$, which in turn were faster than those following random sentences $[F(1,37)=15.6, p<.001]$.

Examination of the error rates suggests that the subjects were more likely to make false negative responses (indicating not in the sentence for old words) for closedclass words than for open class. Thus, we used a measure of ability to discriminate old from new targets, $d^{\prime}$, and a measure of response bias, $\beta$ (see Table 3 ). In this analysis, correct responses to old words were considered hits, and incorrect responses to new words were considered false alarms. The mean $\beta$ for open-class targets was 1.5 (vs. 3.1 for closed-class targets), indicating that the subjects were indeed more likely to respond not in the sentence to closed-class targets $[F(1,37)=35.8, p<.0001]$. There was no significant effect of sentence type on response bias $[F(1,37)=1.0]$, and no significant interaction between sentence type and lexical class $[F(2,74)=0.2]$.

A repeated measures ANOVA of the $d^{\prime}$ scores revealed significant effects of sentence type $[F(1,37)=214.0, p<$
$.0001]$, lexical class $[F(1,37)=29.6, p<.0001]$, and an interaction $[F(2,74)=8.32, p<.0005]$. The main effect of sentence type was due to reduced accuracy in the random condition; there was no performance difference between targets following congruent and syntactic sentences $[F(1,37)=0.05]$. Similarly, the interaction between sentence type and lexical class reflected the lack of a $d^{\prime}$ difference between open- and closed-class words in the random condition $[F(1,37)=0.004]$. This stands in contrast to the other two sentence types wherein accuracy was greater for open-class targets than for closed-class targets [main effect for lexical class in congruent vs. syntactic, $F(1,37)=39.9, p<.0001$; interaction between sentence type and lexical class, $F(1,37)=0.76$, n.s.]

The behavioral data thus indicate that syntactic organization enhanced the memorability of words, but semantic structure provided no additional advantage. This result may seem to be at odds with results from experiments using similar stimulus materials, in which semantic structure typically leads to better memory performance than does syntactic structure alone. However, we tested recognition for only a single word per sentence, whereas early work on the influences of semantic and syntactic structure assessed the ability to repeat or recognize all stimulus words (e.g., Miller \& Isard, 1963; Wang, 1970). For individual words, Miller and Isard (1963) noted an increment of only $1.7 \%$ accuracy due to the addition of semantic structure. This difference was amplified by the demand to produce each successive word in the string correctly; when judged by performance on the entire string, the difference between their congruent and syntactic conditions grew to $9.3 \%$. A more demanding task such as this might have resulted in differential performance on the congruent and syntactic sentences of the present experiment.

The reduced accuracy for the closed-class words relative to that for the open-class words was a predictable result, given that function words have proved less salient or accessible in other tasks (Drewnowski \& Healy, 1977; Haber \& Schindler, 1981). Of greater interest is the observation that this difference obtained only in sentences possessing a syntactic structure. On the basis of a similar pattern of results in an on-line letter-detection task, Rosenberg and colleagues (Rosenberg, Zurif, Brownell, Garrett,

Table 3

Behavioral Performance

\begin{tabular}{|c|c|c|c|c|c|c|}
\hline & \multicolumn{2}{|c|}{ Old Words } & \multicolumn{2}{|c|}{ New Words } & \multirow[b]{2}{*}{$d^{\prime}$} & \multirow[b]{2}{*}{$\beta$} \\
\hline & RT & \% Errors & RT & $\%$ Errors & & \\
\hline \multicolumn{7}{|c|}{ Congruent } \\
\hline Open class & $907 \pm 31$ & 2.6 & $953 \pm 35$ & 1.2 & $4.2 \pm .1$ & $1.9 \pm .3$ \\
\hline Closed class & $1,031 \pm 35$ & 6.2 & $1,006 \pm 33$ & 2.4 & $3.7 \pm .1$ & $3.2 \pm .5$ \\
\hline \multicolumn{7}{|c|}{ Syntactic } \\
\hline $\begin{array}{l}\text { Open class } \\
\text { Closed class }\end{array}$ & $\begin{array}{r}917 \pm 30 \\
1,021 \pm 50\end{array}$ & $\begin{array}{l}1.8 \\
6.7\end{array}$ & $\begin{array}{r}955 \pm 36 \\
1,066 \pm 34\end{array}$ & $\begin{array}{l}1.7 \\
2.4\end{array}$ & $\begin{array}{l}4.2 \pm .1 \\
3.6 \pm .1\end{array}$ & $\begin{array}{l}1.4 \pm .2 \\
3.0 \pm .4\end{array}$ \\
\hline \multicolumn{7}{|c|}{ Random } \\
\hline $\begin{array}{l}\text { Open class } \\
\text { Closed class }\end{array}$ & $\begin{array}{r}923 \pm 28 \\
1,025 \pm 39 \\
\end{array}$ & $\begin{array}{l}11.2 \\
18.4 \\
\end{array}$ & $\begin{array}{r}973 \pm 33 \\
1,140 \pm 44 \\
\end{array}$ & $\begin{array}{l}9.1 \\
7.0 \\
\end{array}$ & $\begin{array}{l}2.6 \pm .1 \\
2.6 \pm .1\end{array}$ & $\begin{array}{l}1.3 \pm .4 \\
3.0 \pm .5\end{array}$ \\
\hline
\end{tabular}

Note-Reaction times and standard errors are given in milliseconds. 
\& Bradley, 1985) concluded that "the fact that the normal open-class-closed-class difference is significant in the prose condition but not in the scrambled condition suggests that the invisibility of closed-class items is in some way dependent upon sentence parsing and interpretation" (p. 299).

It is not entirely clear how strong Rosenberg et al. (1985) believe the dependency to be; their statement seems to imply that sentence parsing enforces "invisibility" upon the closed-class items, with the further implication that closed-class words should be more accessible or visible outside a syntactically structured context. Because Rosenberg et al. (1985) present only the open/closed differences, rather than the mean performance values for the two vocabulary types in their two prose conditions, the implication cannot be evaluated. In the present data, closed-class performance was better in the congruent and syntactic conditions than in the random condition, although open-class items benefited even more from the presence of syntactic structure. The most defensible conclusions we can draw from the present data are that (1) the different word types are equally difficult to recognize without the aid of a syntactic structure, (2) the memorability of both vocabulary types is aided by such structure, and (3) content words are more memorable than are function words when a word string is sentence-like.

\section{ERPs: Global Effects of Sentence Type}

The differentiation between the random word strings and the two structured sentence types in the postsentence recognition memory task was mirrored in the overall brain activity generated as the subjects read these different sentence types. Before examining the brain responses elicited by various word types, we averaged the responses to the three sentence types on a long time scale that included ERPs to the first seven words of each sentence. ${ }^{3}$ Averages of this type are of limited utility because they combine responses to individual words based solely on ordinal sentence position, irrespective of lexical class or frequency. These averages were, however, instructive in the present case. Beginning around the fourth word, the random sentences were differentiated from the other two sentence types by a low-frequency, prolonged positive shift (visible in Figure 1A).

Event-related brain responses are not typically recorded on such a long time scale, and there is relatively little information relating such low-frequency responses to cognitive processes. Insofar as we have previously examined slow potentials across the course of normal sentences, these have been absent or negative-going (Kutas, Van Petten, \& Besson, 1988). Within the sparse human literature on low-frequency potentials, the amplitude of a slow negative shift (over tens of seconds) in a visual tracking task has been correlated with the difficulty of the task and the accuracy of performance (McCallum, Cooper, \& Pocock, 1988). In the animal literature, studies of the sleep-wake cycle and the effects of stimulant and depressant drugs have related sustained negative shifts of surface cortical potential to states of increasing arousal or activation and slow positive shifts to states of decreased arousal (see McCallum, 1988, for a review).

Extending this general correlation to the present observations would suggest that the subjects were less actively engaged in reading the random word strings than they were in reading the well-structured sentences. Random or scrambled word strings have often been used as a baseline condition to assess the influence of sentence context on word recognition (Forster, 1981; Foss, 1982; Marslen-
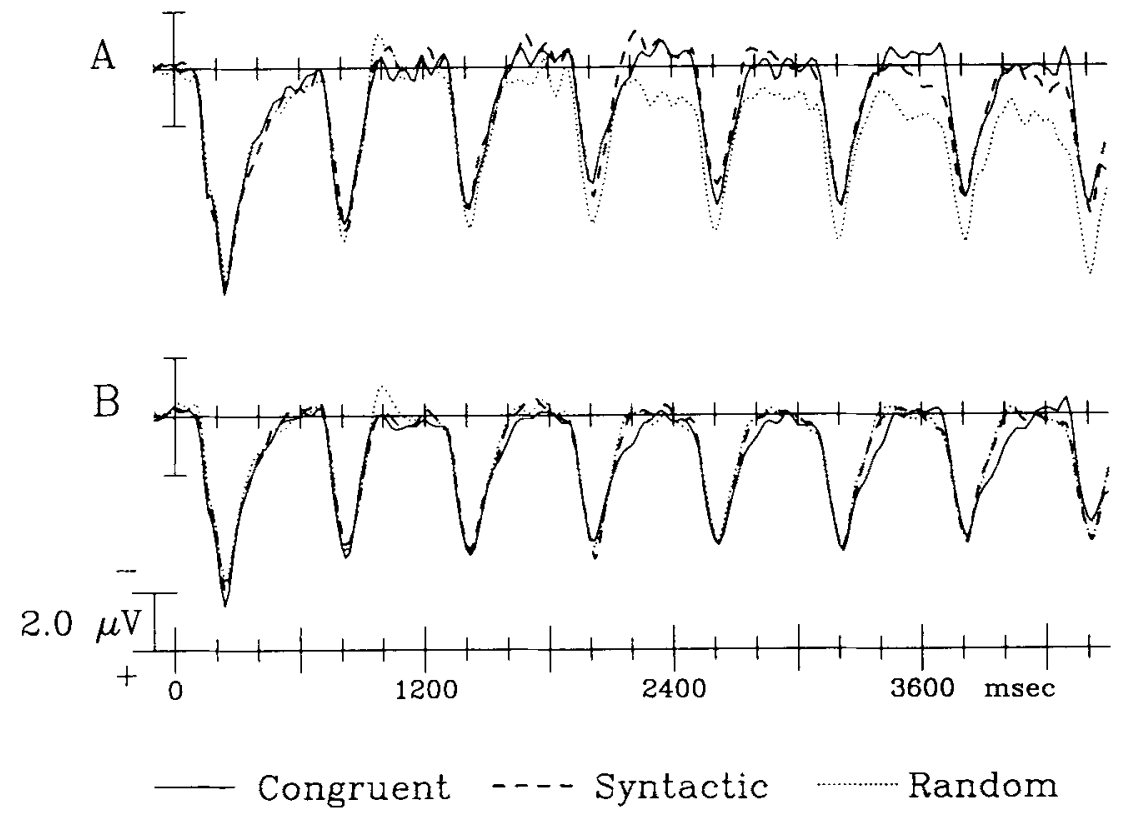

Figure 1. A. Grand average ERPs at C3 for the first seven words of each sentence type, unfiltered. B. The same data after applying a digital highpass filter to the EEG. 
Wilson \& Tyler, 1980; O'Seaghdha, 1989; Sharkey \& Sharkey, 1989; Simpson, Peterson, Casteel, \& Burgess, 1989), although some of these investigators have acknowledged skepticism as to the appropriateness of this baseline. The present results provide direct observational evidence that assigning the same task to random and structured word strings may not induce subjects to treat them with the same degree of interest.

The primary focus of the present experiment was in the interactions between lexical variables and sentence type; the slow positive potential proved to be an obstacle to the data analyses as planned. The differential prestimulus baseline for individual words makes it impossible either to compare the ERPs elicited by words occurring early and late in a random sentence or to compare those elicited by words occurring in a random sentence and words in the same position of the other sentence types. We therefore separated this global effect of sentence type from the more specific activity elicited by single words. The differential frequency spectrum of the two types of ac- tivity allowed us to accomplish this by digitally filtering the raw EEG to remove activity below $1 \mathrm{~Hz}$ before averaging the responses into ERPs. ${ }^{4}$ The success of this endeavor can be evaluated in Figure 1B, which shows the ERPs to the first seven words of each sentence type after filtering. The analyses reported below are based on the filtered data, except as noted.

We will turn now to the ERPs elicited by single words. The data from open-class words are presented first, followed by the responses to closed-class words and a comparison of the pattern of results for the two.

\section{Open-Class Words: Effects of Sentence Type and Word Position}

The most basic question posed in this experiment was whether or not imposing some syntactic structure on a word string would influence the processing of individual words in a manner similar to semantic context, although perhaps to a lesser degree. Figure 2 shows that for openclass words, the ERPs elicited by words in syntactic
Open

Class
Closed

Class

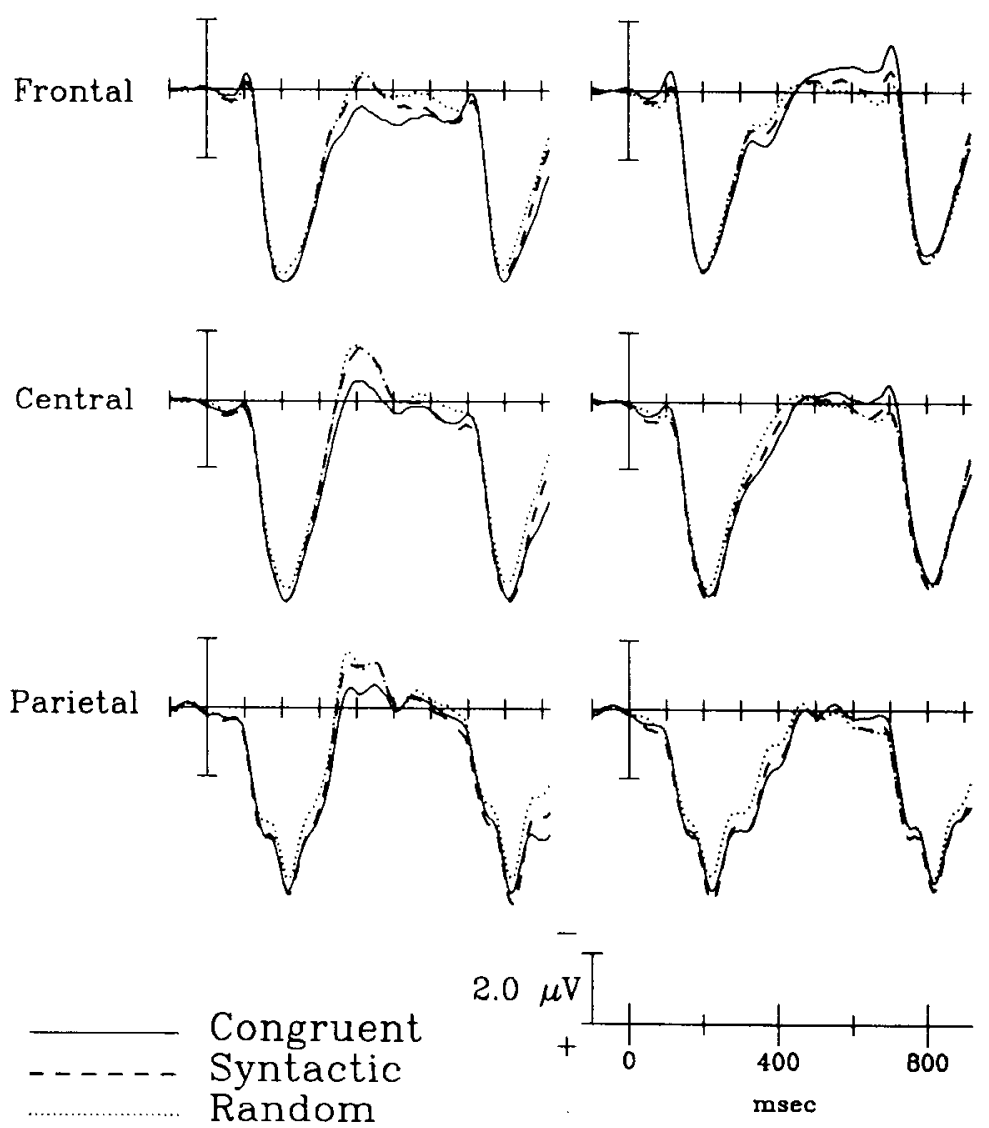

Figure 2. Grand average ERPs elicited by sentence-intermediate words. Midline electrode locations $\mathrm{Fz}, \mathrm{Cz}$, and $\mathrm{Pz}$. 
strings were very similar to those in random strings. The ERPs elicited by congruent words differed from both, suggesting that only semantic context was effective.

A secondary means of addressing the same question is to evaluate the influence of word position. For the relatively short, textually independent sentences used in this study, there is a rough equivalence between the position of a word within its sentence and the amount of context potentially applicable to its identification. For all sentence types, the first word must be processed without the benefit of preceding context. For subsequent words, the amount of context that readers actually use may include the entire sentence fragment up to that point or may be restricted to the immediately preceding word or two. A significant linear effect of word position would support the former conclusion, whereas the absence of a linear trend would suggest a local context effect or none at all. The influences of word position and sentence type on N400 amplitude for intermediate words are shown in Figure 3. Sentencefinal words will be considered separately since these elicit characteristic ERPs that differ from those to intermediate words.

In the initial statistical analyses, the different sentence types were contrasted by ANOVAs with trend analyses taking sentence type, word position (five levels), and electrode location (10 sites) as factors. Since the particular statistical program we used evaluates additional trend components up to one less than the number of levels of the variable under consideration (BMDP 2V; Dixon, 1985), the results include the effect of the second (quadratic), third (cubic), and fourth power (quartic) of word position on the amplitude of the N400. Although we predicted a linear effect of word position for congruent

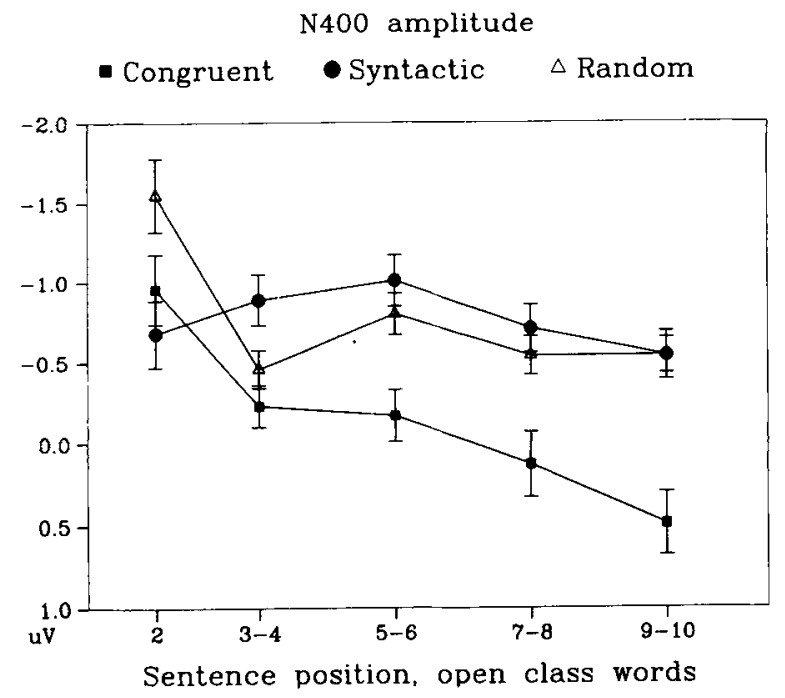

Figure 3. The mean voltage level between $300-$ and $500-\mathrm{msec}$ poststimulus (the N400 latency band) is plotted against word position. The ERP measure is collapsed across all of the scalp recording sites. The data here are for intermediate open-class words in the three sentence conditions. sentences, we have no reason to believe that the higher order trends are meaningful.

Comparing syntactic and random sentences yielded neither a significant main effect of sentence type $[F(1,37)$ $=0.14]$ nor an interaction between sentence type and linear position trend $[F(1,37)=3.47, p=.07]$. In contrast, comparing congruent sentences to either the syntactic or the random sentences yielded main effects of sentence type $[F(1,37)=33.3, p<.0001$, for congruent vs. syntactic; $F(1,37)=27.6, p<.0001$, for congruent vs. random], as well as interactions between sentence type and the linear trend for position $[F(1,37)=18.0, p<$ .0001 , for congruent vs. syntactic; $F(1,37)=28.0, p<$ .0001 , for congruent vs. random].

Additional analyses were performed on each sentence type individually. The linear trend of $\mathrm{N} 400$ amplitude across sentence position was significant for congruent sentences $[F(1,37)=27.3, p<.0001]$, but not for syntactic ones $[F(1,37)=1.76$, n.s.]. None of the other orthogonal trend components were significant in either case. For random sentences, the linear component was significant $[F(1,37)=11.5, p<.002]$, as were the quadratic $[F(1,37)=4.47, p<.05]$, cubic $[F(1,37)=6.60$, $p<.02]$, and quartic $[F(1,37)=6.47, p<.02]$. The data in Figure 3 suggest that this complicated pattern of results for the random sentences may be due to a single data point, namely the amplitude of the $\mathrm{N} 400$ for Word 2 . In fact, an ANOVA excluding Word 2 (four levels of sentence position) yielded no significant trend components for N400 amplitude across the random sentences [for linear, $F(1,37)=0.01$; for quadratic, $F(1,37)=1.53$; for cubic, $F(1,37)=1.41$ ]. By comparison, excluding Word 2 from the congruent-sentence data did not eliminate the significant linear trend due to sentence position $[F(1,37)=16.9, p<.0002]$.

There was thus no evidence that the constraints available in the syntactic sentences were capable of reducing N400 amplitude for open-class words, whereas semantic context produced a linear decrement in amplitude across the course of a sentence. The cumulative nature of this effect indicates that the semantic context utilized during the processing of each open-class word was incremental, comprising as much of the sentence fragment as had been seen up to that point.

\section{Open-Class Words: Effects of Word Frequency}

The ERPs elicited by high- and low-frequency words in different sentence positions are shown in Figure 4. The larger N400 for low-frequency words persisted throughout the syntactic and random sentences but was not present for the latter part of congruent sentences. The critical statistical test to evaluate this impression was to determine whether or not there was an interaction between word frequency and the linear trend in N400 amplitude due to sentence position (i.e., to evaluate whether or not the slope of the word-position effect was steeper for lowfrequency words than it was for high-frequency words). 
Congruent Syntactic Random

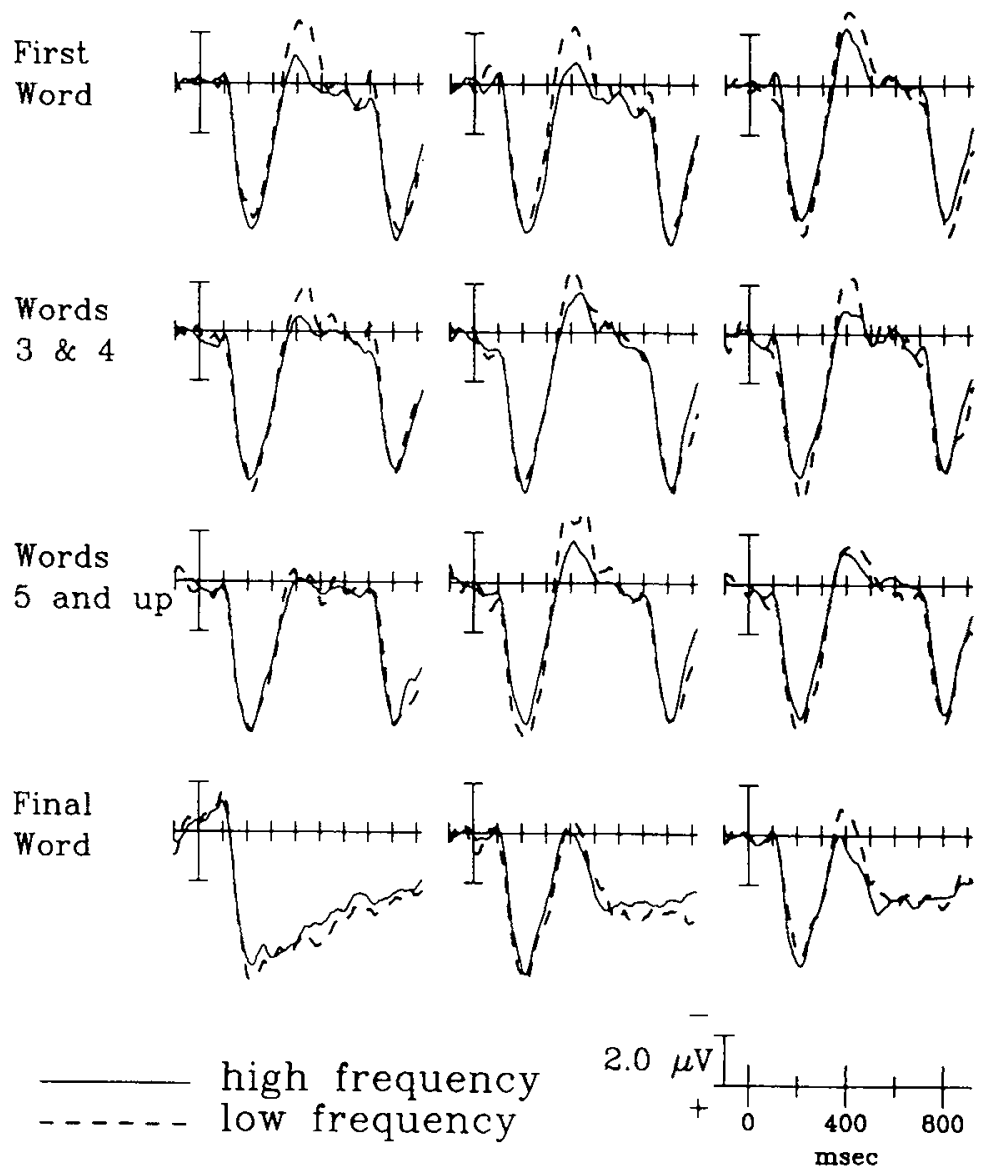

Figure 4. Grand average ERPs elicited at the central midline site $(\mathrm{Cz})$ for highand low-frequency open-class words broken down by sentence type and word position. First Word refers to the first open-class word of a sentence.

For congruent sentences, this interaction was significant $[F(1,37)=6.90, p<.02]$, whereas for syntactic and random sentences, it was not $[F(1,37)=0.09$, and $F(1,37)=0.13]$. There was no evidence of a difference between syntactic and random sentences with regard to frequency effects $[F(1,37)=29.1, p<.0001$, for the main effect of frequency; $F(1,37)=3.78$, n.s., for the interaction between sentence type and frequency].

The syntactic contexts were not effective in suppressing the word-frequency effect, whereas semantic constraints were. This finding is a refinement of our previous report that some aspect of normal sentence structure can eliminate the word-frequency effect (Van Petten \& Kutas, 1990a).

\section{Final Words}

In Figure 5, it can be seen that the final words of congruent sentences differ from both intermediate words and the final words of the other sentence types in eliciting no N400 activity. ${ }^{5}$ The congruent final words differed sig. nificantly from both of the other sentence types in the
N400 latency range [congruent vs. syntactic, $F(1,37)=$ $149.9, p<.0001$; congruent vs. random, $F(1,37)=$ $123.0, p<.0001]$, but there was no difference between syntactic and random words $[F(1,37)=2.61$; interaction with electrode site, $F(12,444)=2.72, \epsilon=.19$, n.s. $]^{6}$ Figure 5 shows that the $\mathbf{N} 400$ to both syntactic and random final words was slightly larger at right hemisphere sites than at left hemisphere sites, but this effect did not reach significance $[F(1,37)=2.75]$.

Figures 4 and 5 show that the ERPs to the final words of all three sentence types differ from intermediate words in the occurrence of a broad positive wave of maximal amplitude at parietal sites. For congruent final words, this positivity dominates the recording epoch; for syntactic and random words, it is visible following the $\mathrm{N} 400$. A similar late positivity has been characteristic of ERP responses to final words in previous experiments (Friedman, Simson, Ritter, \& Rapin, 1975; Kutas \& Hillyard, 1980a, 1980c, 1982). Of interest here is that, unlike any aspect of the ERPs to intermediate open-class words, the positive wave differentiated between the final open-class words of the 
Final words

Left

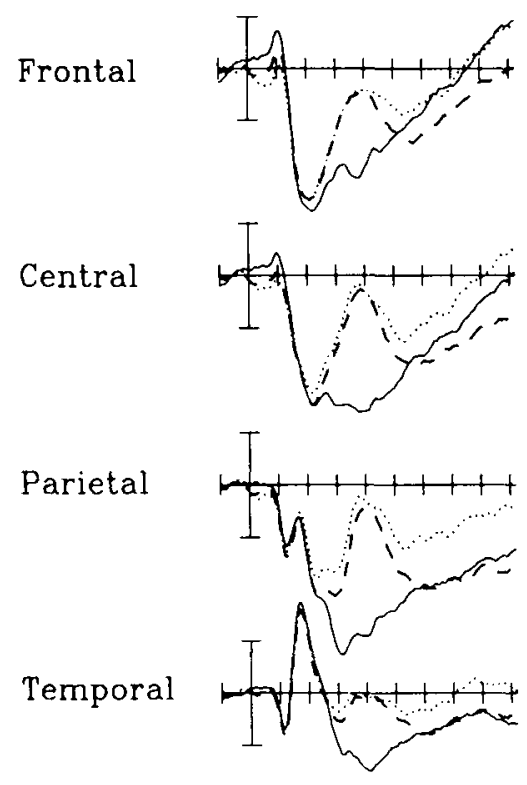

Occipital

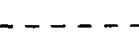

$----$
Right
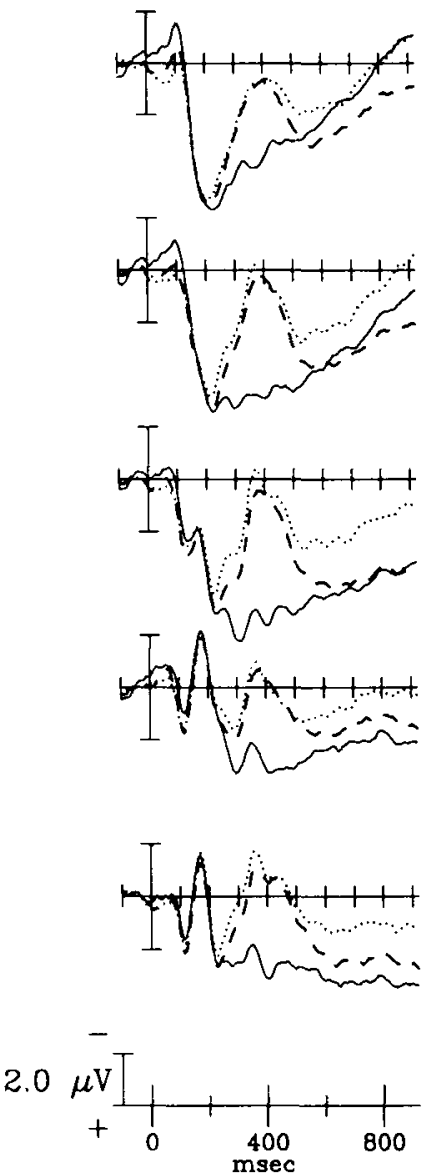

Figure 5. Grand average ERPs elicited by the final words of the three sentence types. Shown are lateral electrode sites F3, F4, C3, C4, P3, P4, T5, T6, $O 1$, and 02 . This data was not subjected to the highpass digital filter.

syntactic and random sentences. Quantified as the mean voltage between 500 - and 900 -msec poststimulus onset, the late positivity was smaller for random words than for either syntactic sentences $[F(1,37)=48.0, p<.0001]$ or congruent sentences $[F(1,37)=32.9, p<.0001]$. In contrast, there was no main effect of sentence type in the comparison of syntactic and congruent conditions $[F(1,37)=$ $0.01]$, but a significant interaction between sentence type and recording site indicated that these positivities had a different distribution across the $\operatorname{scalp}[F(12,444)=15.1$, $\epsilon=.23, p<.0001]$.

Further analyses of the scalp distributions of the late positivity were conducted via ANOVAs, taking data from the lateral recording sites only, so that the dimensions of laterality (left or right) and anterior to posterior (frontal, central, parietal, occipital, and temporal) could be included as factors. These showed that, while the late positivity was reliably larger over the right than the left hemisphere for congruent final words, it was only mar- ginally asymmetric for the syntactic sentences [main effect of laterality for congruent words, $F(1,37)=26.3$, $p<.0001$; for syntactic words, $F(1,37)=3.59, p=$ .07]. In previous work, the late positivity following congruous sentence completions has not shown a consistent lateral asymmetry, being sometimes larger over the right, the left, or equipotential between the two hemispheres (Friedman et al., 1975; Kutas \& Hillyard, 1980a, 1980c, 1982; Kutas, Hillyard, \& Gazzaniga, 1988). ${ }^{7}$ The import of the differential asymmetry observed here for the different sentence types is not yet subject to interpretation, but deserves further research.

In the anterior-posterior dimension, the late positivity was of maximum amplitude at parietal scalp sites, intermediate at central and occipital sites, and smallest at frontal and temporal sites. ${ }^{8}$ This pattern suggests that it should probably be considered a member of the $\mathrm{P} 300$ family of responses, which have been linked to a variety of cognitive processes in both language and nonlanguage para- 
digms (see Donchin \& Coles, 1988; Johnson, 1988; Verleger, 1988). Friedman et al. (1975) first observed that sentence-final words elicited P300-type potentials, even when the sentences were familiar to the subjects before the experiment and repeated many times during the experiment, thereby carrying no new information. Friedman et al. characterized the late positivity as reflective of a "syntactic closure" operation and the realization that the sentence was over.

The reduced amplitude of the late positivity for the final words of the random strings used in the present experiment is consistent with this broad description. These words did not complete a structural or semantic unit. Furthermore, the random "sentences" were of variable length and, from a subject's point of view, were arbitrarily and unpredictably truncated at different points; if a subject missed the period accompanying the last word, he/she may not have immediately realized that the sentence was indeed over. The dissociation between the positive wave and the information content of the eliciting word demonstrated by Friedman et al. (1975) suggests that this difference between random and syntactic final words does not reflect any specific aspect of the word recognition process.

\section{Closed-Class Words: Effects of Sentence Type}

Figure 2 depicts two effects of sentence type on closedclass words. In the N400 latency range (300- to 500-msec poststimulus), the congruent sentences elicited less negativity than did the syntactic, which in turn elicited less than the random [main effects of sentence type, congruent vs. syntactic, $F(1,37)=5.20, p<.05$; syntactic vs. random, $F(1,37)=5.53, p<.05$; congruent vs. random, $F(1,37)=25.6, p<.0001]$. However, this negativity was not influenced by the ordinal position of a word within its sentence: Neither the main effect of word position nor the linear trend associated with word position were significant in congruent sentences $[F(4,148)=1.02$ and $F(1,37)=0.13]$.

Subsequent to the $\mathrm{N} 400$, a different effect of sentence type can be seen in Figure 2. In the congruent sentences, closed-class words elicited a broad ramp-shaped negativity most prominent at the frontal electrodes. Previously, we have observed a similar late frontal negativity in association with closed-class words embedded in congruent sentences (Kutas \& Hillyard, 1983; Kutas, Van Petten, \& Besson, 1988). In the current case, this potential was much smaller or absent in the syntactic and random sentences [main effect of sentence type for the inclusive ANOVA, $F(2,74)=11.3, \epsilon=1.00, p<.0001]$, which did not differ from each other $[F(1,37)=2.52$, n.s.]. The late negativity was bilaterally symmetric [sentence $x$ laterality interaction, $F(2,74)=1.79$ ], and largest frontally [sentence $\times$ anterior-posterior, $F(8,296)=3.39, \epsilon=.40$, $p<.02]$.

In contrast to the $\mathrm{N} 400$, the late frontal negativity was sensitive to word position. Figure 6 shows that this negativity increased across the course of congruent sentences, but was unaffected by word position in either the syntactic

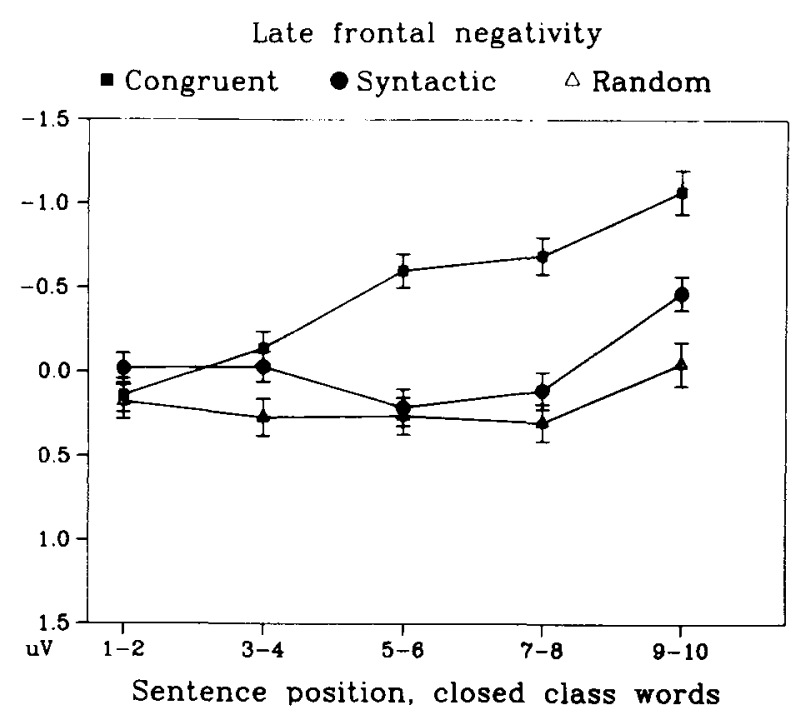

Figure 6. The mean voltage between 500 - and 700 -msec poststimulus is plotted against word position. The measure is collapeed across frontal and central recording sites $\mathrm{Fz}, \mathrm{F3}, \mathrm{F4}, \mathrm{C3}, \mathrm{Cz}$, and $C 4$. The data here are for initial and intermediate closed-class words in the three sentence types.

or random sentences [linear trend, congruent, $F(1,37)=$ $19.5, p<.0001$; syntactic, $F(1,37)=1.93$, n.s.; random, $F(1,37)=1.21$, n.s.]. The word-position effect for congruent sentences was most pronounced frontally, where the potential was largest [interaction of linear trend for word position $\times$ linear trend for the anterior-posterior dimension, $F(1,37)=11.8, p<.002$ ].

The condition specificity of the late frontal negativity indicates that it is not tied to any inherent difference between the lexical classes, but depends on sentence processing. The morphology and scalp distribution of this potential are similar to the ERP component referred to as the contingent negative variation (CNV). The prototypical CNV paradigm is a paired-stimulus situation wherein an imperative stimulus follows a warning stimulus by a fixed interval; a negative potential, the CNV, develops during the interstimulus interval. The CNV has been shown to increase in amplitude with increases in motivation and task complexity (Irwin, Knott, McAdam, \& Rebert, 1966; McAdam, Irwin, Rebert, \& Knott, 1966; McCallum \& Papakostopoulos, 1973). The earliest formulations of the cognitive events underlying the CNV characterized these as anticipation or preparation for incoming information (Hillyard, 1973; Walter, Cooper, Aldridge, McCallum, $\&$ Winter, 1964). Physiological data have supported the idea that such negative shifts reflect cortical activation (see McCallum, 1988; Pirch, Corbus, Rigdon, \& Lyness, 1986) ${ }^{9}$

Such ideas seem easily applicable to the present paradigm. Sentence words were presented at a fixed rate, allowing the subjects to anticipate the timing of the next word with reasonable precision. Furthermore, this rate was the same for all words, whereas in more natural reading situations, people often fail to fixate some percent- 
age of function words (Carpenter \& Just, 1983; O'Regan, 1979). The fixed time between words in the present paradigm may have then resulted in a "waiting interval" that was longer following closed than open-class words. However, this cannot be the whole story. Since the late frontal negativity was unique to closed-class words in meaningful sentences and grew larger as these sentences progressed, it was clearly related to the functional role of these words in their context. This role is to indicate the proper relations among the content words of the sentence. Given that closed-class words occur primarily at the beginnings of phrases, the mental event underlying the frontal negativity might be characterized as not just "waiting for the next word" but perhaps as "waiting for the head of the phrase." The fact that this CNV-like potential was restricted to the congruent sentences is consistent with the view that the subjects were more actively engaged in processing these than either variety of nonsensical word strings.

\section{The Impact of Context on Open- and \\ Closed-Class Words}

The analyses presented thus far have considered openand closed-class words separately. These have indicated that the open-class words were influenced by semantic context alone (i.e., the difference between the syntactic and random conditions was not significant), whereas closed-class words were influenced by both semantic and syntactic context (i.e., there was a three-way difference among the conditions). In this section, we compare the amplitude and scalp distribution of the context effects for the two lexical classes directly.

The effect of an experimental manipulation is most easily visualized in a difference wave: Figure 7 depicts the difference between no contextual support for individual words (i.e., random sentences) and normal contextual support (i.e., congruent sentences). For open-class words, the context effect takes the form of a monophasic nega-
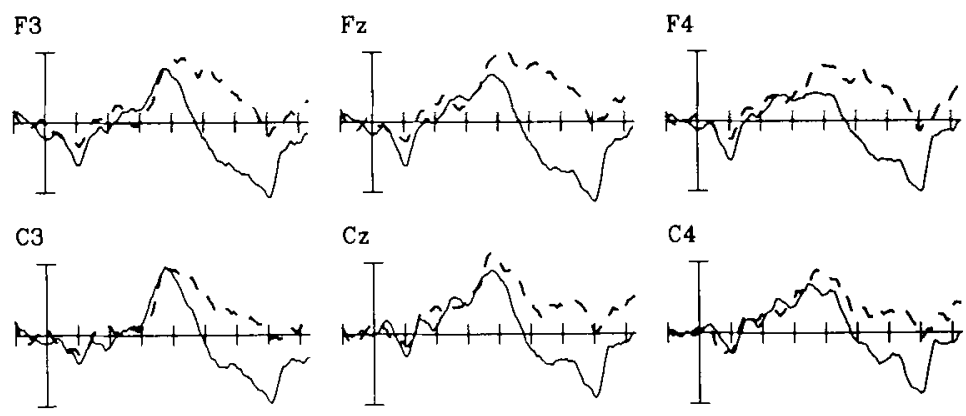

C4
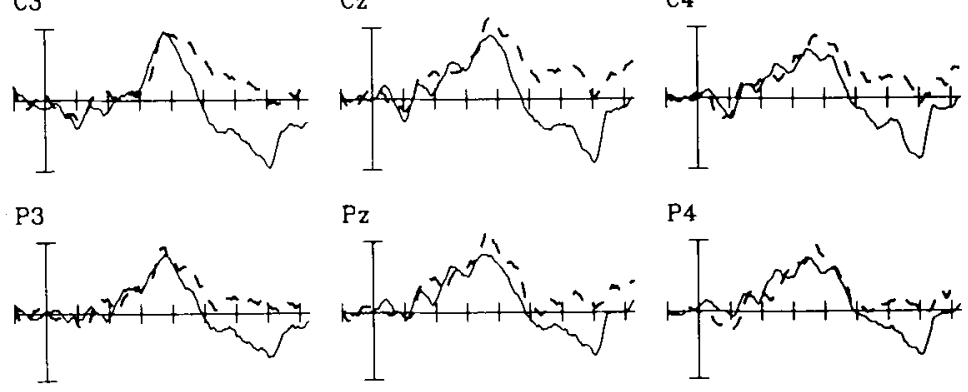

P4
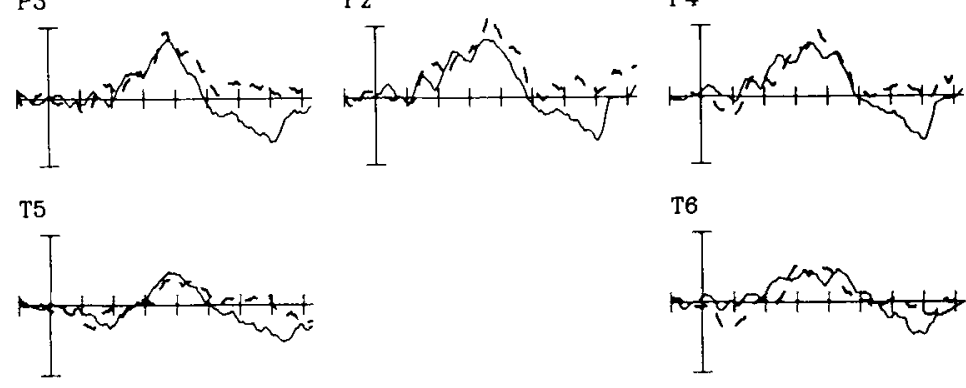

T6
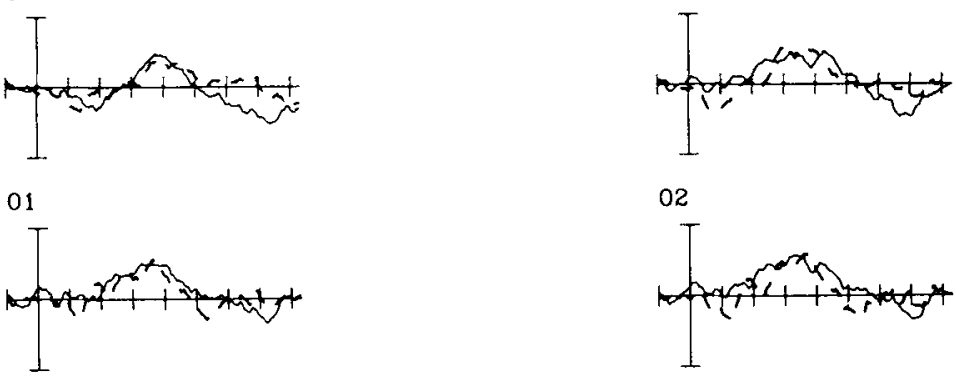

02
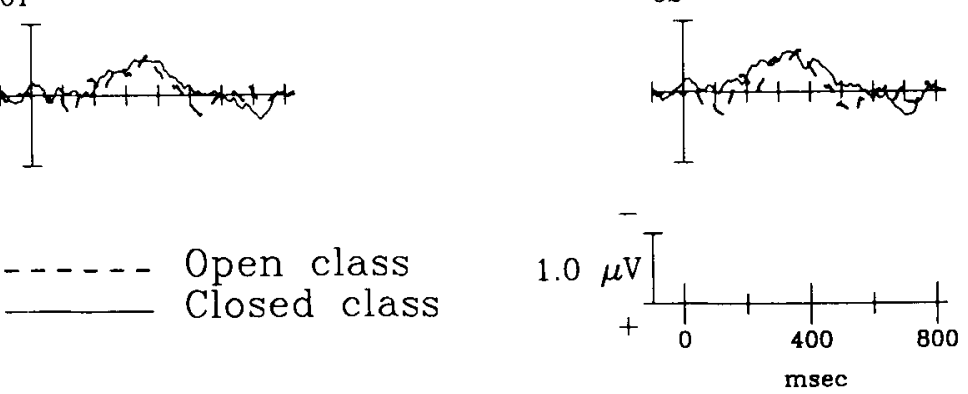

Figure 7. Difference waves for intermediate open- and closed-class words. Both waveforms are the result of subtracting the ERP elicited by words in congruent sentences from that elicited by words in random sentences. Note the direction of the subtraction operation; negativity in the difference wave was due to the fact that the ERP in the random condition was more negative than was the ERP in the congruent condition, whereas positivity in the difference wave was due to the fact that the congruent ERP was more negative than was the random ERP. 
tivity extending from about 200 - to 500 -msec poststimulus, which we consider an $\mathrm{N} 400$ effect. For closed-class words, the difference wave consists of an $\mathrm{N} 400$ followed by a positivity that is largest over the anterior scalp. The late positivity in the closed-class difference wave is the inverse of the late frontal negativity observed in the original ERP to closed-class words in congruent sentences, described above. Here, we will concern ourselves with the similarities and differences of the $\mathrm{N} 400$ elicited by open- and closed-class words and the N400's responsiveness to semantic and syntactic context.

In all three sentence types, closed-class words elicited smaller N400s than did open-class words [congruent, $F(1,37)=13.3, p<.001$; syntactic, $F(1,37)=41.9$, $p<.0001$; random, $F(1,37)=28.3, p<.0001$ ]. However, in the comparison of the difference waves shown in Figure 7, there was no significant difference between the impact of context on open- and closed-class words in the N400.

Additional difference waves were formed and analyzed in order to isolate the specific effects of semantic and syntactic context for both lexical classes. Semantic context effects were defined as the difference between the ERPs in congruent and syntactic sentences, whereas syntactic context effects were defined as the difference between syntactic and random sentences. These semantic and syntactic difference waves were calculated separately for openand closed-class intermediate words.

The mean amplitudes of each difference wave between 300 - and 500 -msec poststimulus were analyzed via an ANOVA with type of context (semantic vs. syntactic), lexical class (open or closed), and electrode site (13 levels) as factors. This omnibus ANOVA yielded a significant main effect for type of context $[F(1,37)=6.00, p<.02]$ and an interaction between type of context and lexical class $[F(1,37)=5.78, p<.05]$. The main effect of lexical class was not significant $[F(1,37)=2.14]$. The main effect of type of context and the interaction reflect the fact that semantic context affected the responses to both openand closed-class words, whereas syntactic context influenced only the responses to closed-class words. The pairwise comparisons between nonzero effects are of greater interest. Semantic context had a larger impact on open-class words than on closed-class words $[F(1,37)=$ $7.81, p<.01]$. Closed-class words were equally influenced by semantic and syntactic context $[F(1,37)=0.01]$.

The distributions of these different context effects across the scalp are also of interest; some of the ANOVAs reported above included significant interactions with electrode site. However, such interactions are not considered to be valid indicators of differences in scalp distribution when there are overall amplitude differences between effects, due to the additive nature of the ANOVA (McCarthy \& Wood, 1985). ${ }^{10}$ Therefore, before examining the spatial distribution of the effects, the data were normalized so that each difference wave had the same overall mean amplitude across recording sites. These ANOVAs included the normalized amplitudes from the lateral record- ing sites with factors of laterality (right and left) and anterior to posterior (frontal, central, parietal, occipital, and temporal).

These analyses showed that the semantic context effect was larger over the right hemisphere for open-class words, but larger over the left for closed-class words [interaction of class $\times$ laterality, $F(1,37)=18.1, p<.0001$ ]. Although this differential asymmetry was significant, it was extremely small, consisting of a $6 \%$ difference between the hemispheres for open-class words and a $3 \%$ difference for closed-class words. Elsewhere, we have noted that the typical right-greater-than-left asymmetry of the N400 is reduced by a family history of lefthandedness (Kutas \& Hillyard, 1982; Kutas, Van Petten, $\&$ Besson, 1988). Performing the above analysis with data from only the subjects who were right-handed and reported no left-handed relatives resulted in somewhat larger asymmetries - for the open class, $9 \%$ (right greater), and for the closed class, $3.5 \%$ (left greater) $[F(1,19)=12.3$, $p<.005]$. The class $\times$ anterior-posterior interaction was not significant for either the entire group or the subgroup of subjects.

The scalp distribution comparison between semantic and syntactic effects on closed-class words yielded no significant interactions with electrode site [type of context $x$ laterality, $F(1,37)=0.58$; type of context $\times$ anteriorposterior, $F(4,148)=2.71, \epsilon=.53$ ].

\section{DISCUSSION}

A number of previous studies have been devoted to describing the influence of sentence context on the brain activity elicited by individual words (for reviews, see Fischler \& Raney, in press; Kutas \& Van Petten, 1988). The present experiment was designed to extend past work by evaluating the separate contributions of semantic and syntactic context and by analyzing the ERPs to closedclass words in more detail. The remainder of the discussion will take up the two major concerns of the experiment: the processing advantages that accrue to words occurring within semantic and syntactic structures and comparisons between open- and closed-class words.

We have evaluated processing differences between normal, syntactically structured, and random word strings via a number of measures in the present experiment. These included a short-term memory task and four measures of brain activity provided by the ERP: (1) the low-frequency positive shift seen during random strings, (2) the late parietal positive wave elicited by sentence-final words, (3) the N400 elicited by individual words, and (4) the late frontal negativity observed in association with closed-class words. Every measure differentiated the meaningful congruent sentences from the random strings.

Several differences between the syntactic and random conditions also were observed, but we have already suggested that some of these do not reflect specifically syntactic operations. Considering both the human and the animal literature on slow potentials, we believe that the 
slow positive shift during the random sentences reflected a general decrease in arousal/attention while these unstructured strings were being read. Filtering the low-frequency potential from the EEG did not remove the underlying cognitive events or consequences of the slow shift. The poor recognition performance for targets following random word strings may have been one such consequence. The third distinction between the data from the syntactic and random conditions was in the larger amplitude of a P300-like potential elicited by the final words of syntactically structured strings. Given work on the P300 outside of psycholinguistic paradigms, we found it most parsimonious to interpret this difference as reflective of a general cognitive operation, one closely tied to a subject's degree of certainty as to when an experimental "sentence" is finished.

In contrast to the $\mathrm{P} 300$, the $\mathrm{N} 400$ component of the ERP has been more closely tied to factors thought to play a role in word recognition. The absence of any $\mathrm{N} 400$ difference between open-class words in syntactic and random sentences was thus somewhat surprising to us and lends itself to two different interpretations: (1) the N400 measure, while a useful index of semantic constraints on the processing of individual words, is insensitive to syntactic constraints, or (2) the sort of information that structured but meaningless sentence fragments offer is not, in fact, strong enough to facilitate the processing of subsequent open-class words. Before concluding that the $\mathrm{N} 400$ was insensitive to the benefits that a syntactic structure can offer for the recognition of individual words, we review the reaction-time evidence concerning the nature and size of the processing benefits that might be expected from syntactic priming in the visual modality.

Goodman, McClelland, and Gibbs (1981) obtained faster lexical decision times for nouns preceded by possessive pronouns and verbs preceded by nominative pronouns than when the cases of the preceding pronouns were inappropriate. However, this effect was small $(19 \mathrm{msec})$ and disappeared when the same word pairs were intermixed with semantically related pairs. Using similar stimuli, Seidenberg, Waters, Sanders, and Langer (1984) found that, even in the absence of semantically related pairs, a syntactic priming effect could be obtained only with a lexical decision and not with a speeded naming task. This task difference has held even with inflected Serbo-Croatian words, which might have been expected to produce stronger effects than would English since possessive pronouns must agree with their nouns in gender, number, and case (Carello, Lukatela, \& Turvey, 1988; Lukatela, Kostic, Feldman, \& Turvey, 1983; Lukatela et al., 1982). It has been argued that lexical decisions involve more task-specific strategic processing than the pronunciation and are therefore more susceptible to factors that have no role in normal reading (Balota \& Chumbley, 1984; Seidenberg et al., 1984). The task specificity of syntactic priming effects stands in contrast to semantic priming effects, which can be demonstrated with a variety of tasks. Clearly, syntactic priming with single-word contexts is a small and fragile effect.
More robust syntactic priming effects have been obtained with sentence-fragment contexts. In an elegant series of experiments, Wright and Garrett (1984) initially measured lexical decision times to stimuli like the following (targets are capitalized):

If your bicycle is stolen, you must FORMULATE If your bicycle is stolen, you must BatTERIES For now, the happy family lives with FORMULATE For now, the happy family lives with BATTERIEs

Reaction times were faster for verbs following modal auxiliaries than for verbs following prepositions, and the opposite pattern held for nouns. West and Stanovich (1986) subsequently demonstrated that these effects were not tied to the lexical decision task, but could be obtained with naming as well. However, Wright and Garrett (1984) also found that several types of syntactically appropriate continuations did not result in faster RTs than ungrammatical continuations. For example, despite the fact that noun-noun constructions are fairly common in English (as in "funeral procession," "computer terminal," etc.), these were not responded to more quickly than were ungrammatical verbverb sequences. Noun-main verb constructions did result in faster RTs, presumably because this is a very frequent construction. Similarly, appropriate adjective targets and illegal adjective targets were shown to have equivalent RTs. Priming of an adjective target was demonstrated only when it functioned as the head of a predictable adjective phrase (e.g., "seems very tolerable"). Wright and Garrett's (1984) results suggest that while syntactic context can facilitate the recognition of individual words, this is not a very pervasive phenomenon.

The experiments reviewed above used stimuli that were carefully constructed to maximize the possibility of syntactic priming. The fragility and specificity of the effects obtained suggest that, in practice, a well-formed syntactic structure places few constraints on open-class words or that only a small proportion of words in a typical sentence are subject to such constraints. Work on auditory word recognition has also demonstrated that only the strongest of syntactic constraints yield a significant effect and that this is far weaker than even a minimal semantic context (Tyler \& Marslen-Wilson, 1986; Tyler \& Wessels, 1983). This point can also be argued on the general principles that syntactic structure rarely places narrow constraints on the form class of possible continuations and that many words are ambiguous with respect to their syntactic category. It is thus not surprising that we observed no difference in $\mathrm{N} 400$ amplitude between open-class words occurring in well- and ill-formed word strings. We take this brain potential to be a sensitive index of the degree of contextual constraint operating on an individual word, but, in the case of our syntactic sentences, there was little such constraint on the open-class words.

This argument, that syntactic structure places few constraints on possible open-class sentence continuations, is less likely to hold for closed-class continuations. Several studies have demonstrated that, when confronted with a 
fill-in-the-blank, or cloze, procedure, subjects are much more capable of predicting function than content words (Aborn, Rubenstein, \& Sterling, 1959; Gough, 1983; Smith-Burke \& Gingrich, 1979). In the largest such study, testing 24 subjects with each of a set of 1,380 sentences drawn from popular magazines, Aborn et al. (1959) found that pronouns were predicted with $55 \%$ accuracy and other function words with $63 \%$ accuracy. The accuracy of prediction for content words averaged $28 \%$. These researchers also observed a lower probability of word-class errors (e.g., a noun for a verb, or a conjunction for an article) when the omitted word was a closed-class item. In a more restricted version of this procedure, in which subjects were not given access to the context following the missing word, Gough (1983) obtained lower overall predictability scores, but a similar gap between open- and closedclass words ( $10 \%$ vs. $40 \%)$.

All of the cloze experiments cited above used normal meaningful sentences that cannot tell us what proportion of the constraint on closed-class items can be attributed to formal sentence structure and what can be attributed to semantic content. In the present experiment, we observed effects of both: closed-class words were associated with the least negativity in the N400 latency range when they were embedded in congruent sentences, intermediate $\mathrm{N} 400$ amplitudes were observed in syntactic sentences, and the largest amplitudes were recorded in the random sentences. This stands in contrast to the pattern of results for the open-class words where syntactic and random words elicited equivalent N400s. This contrast suggests that, while constraints on open-class words are primarily semantic in nature, contextual support of closed-class words arises from both semantic and syntactic structure.

The present data do not, however, allow a statement as to whether each function word benefits from both syntactic and semantic context, or whether there are subtypes of function words whose processing is more or less influenced by the different sources of information present in a sentence. The function word classification used here was quite inclusive and averaged across words that seem to possess different degrees of semantic richness (see Flores d'Arcais, 1985, for a discussion of this issue). The importance of distinguishing between different classes of function words is evident in the research of Friederici (1985). Comparing word-monitoring times for two types of German prepositions, one which she suggests is selected by meaning (lexical prepositions) and the other by syntax (obligatory prepositions), Friederici found that only the lexical prepositions benefited from semantic context. A similar breakdown of English closed-class words in a paradigm such as the present one would be of interest.

Although the closed-class items were influenced by surrounding context in both the congruent and the syntactic conditions, they were not subject to any greater constraint near the end of a sentence than near the beginning. This suggests that the context used in the processing of closedclass words is quite local, perhaps consisting of the immediately preceding word or two. This stands in contrast to the cumulative effect of semantic context on openclass words.

The present results also demonstrate that semantic context is capable of suppressing frequency effects for openclass words. The closed-class words, which were the only ones to show a sensitivity to syntactic context, were not sorted for frequency because the experimental sentences included only the more common function words. A number of investigators have demonstrated that closed-class words in isolation are subject to frequency effects (Garnsey, 1985; Gordon \& Caramazza, 1982; Segui, Mehler, Frauenfleder, \& Morton, 1982). Future research with more complex reading material that incorporates lower frequency function words will be needed to determine whether such words will show a context $x$ frequency interaction, and, if so, whether semantic and syntactic context will act in a similar manner.

In each of the sentence conditions, the $\mathbf{N} 400$ was smaller to function words than to content words. This is a highly replicable finding, which in the past has led us to state that there is little or no $\mathbf{N} 400$ activity for closed-class words (Kutas \& Van Petten, 1988; Kutas, Van Petten, $\&$ Besson, 1988). However, we have never before examined the impact of a context manipulation on closed-class words. It is now apparent that when a condition of normal meaningful sentence context is compared with a condition of no contextual support, there is a similar modulation of $\mathrm{N} 400$ amplitude for open- and closed-class words. In conjunction with the other results reviewed here, this suggests that the small-amplitude N400s usually observed for closed-class words may well be due to three factors: the higher frequency, greater likelihood of repetition, and the greater predictability of such words in sentences (for ERP effects of repetition priming, see Besson, Kutas, \& Van Petten, in press; Rugg, 1985; Rugg, Furda, \& Lorist, 1988; Rugg \& Nagy, 1987; Smith \& Halgren, 1987; Van Petten \& Kutas, 1990b). The major difference between the lexical classes observed here was that only closed-class words were responsive to syntactic context. We have argued that this should be considered an informationprocessing effect reflecting the fact that a well-structured sentence fragment provides substantial cues to the identity of subsequent function words but few cues as to the identity of subsequent content words.

The sole support in the current data set for the idea of different and specific brain processors for the two lexical classes was the observation of a small difference in the laterality of the semantic context effect. Across several previous experiments, it has been seen that the amplitude of the $\mathrm{N} 400$ effect on open-class words is somewhat larger over the right hemisphere than over the left hemisphere (Kutas \& Hillyard, 1982; Kutas, Hillyard, \& Gazzaniga, 1988; Kutas, Van Petten, \& Besson, 1988). A small rightsided predominance was seen for the open-class words here as well; in contrast, the $\mathrm{N} 400$ effect for closed-class words was slightly larger over the left hemisphere. Only replication of this laterality difference will suggest how seriously it should be taken. 
On the whole, the current study presents negative evidence for a qualitative difference between the processing of open- and closed-class words. Negative evidence is, of course, never as powerful as positive evidence when trying to determine the identity or nonidentity of two mechanisms. The suggestion that open- and closed-class words are subserved by different brain processors arose from studies of aphasics, a population not studied here. However, claims about normal processing based on neuropsychological data should, eventually, be substantiated by studies of the normal population. Many of the early suggestions that normal subjects showed differential frequency sensitivity, nonword interference, and visual field effects for open- and closed-class words have not been replicated (Chiarello \& Nuding, 1987; Garnsey, 1985; Gordon \& Caramazza, 1982; Kolk \& Blomert, 1985; Petocz \& Oliphant, 1988; Segui et al., 1982). To this list we can add that open- and closed-class words show very similar context effects in scalp-recorded measures of brain activity.

\section{REFERENCES}

Aborn, M., Rubenstein, H., \& Sterling, T. D. (1959). Sources of contextual constraint upon words in sentences. Joumal of Experimental Psychology, 57, 171-180.

Balota, D. A., Chumbley, J. I. (1984). Are lexical decisions a good measure of lexical access? The role of word frequency in the neglected decision stage. Journal of Experimental Psychology: Human Perception \& Performance, 10,340-357.

Besson, M., Kutas, M., \& Van Petten, C. (in press). ERP signs of semantic congruity and word repetition in sentences. In C. H. M. Brunia, A. W. K. Gaillard, A. Kok, G. Mulder, M. N. Verbaten (Eds.), Proceedings of the Ninth International Conference on EventRelated Potentials of the Brain. Tilburg. Germany: Tilburg University Press.

Bradley, D., \& Garrett, M. (1983). Hemisphere differences in the recognition of closed and open class words. Neuropsychologia, 21 , $155-160$.

Bradley, D., Garrett, M., \& Zurif, E. B. (1980). Syntactic deficits in Broca's aphasia. In D. Caplan (Ed.), Biological studies of mental processes (pp. 269-286). Cambridge, MA: MIT Press

Carello, C., Lukatela, G., \&urvey, M. T. (1988). Rapid naming is affected by association, not by syntax. Memory \& Cognition, 16, 187-195.

Carpenter, P. A., \& Just, M. A. (1983). What your eyes do while your mind is reading. In $\mathrm{K}$. Rayner (Ed.), Eye movements in reading: Perceptual and language processes (pp. 275-308). New York: Academic Press.

Chiarello, C., \& Nuding, S. (1987). Visual field effects for processing content and function words. Neuropsychologia, 25, 539-548.

CoWART, W. (1982). Autonomy and interaction in the language processing system: A reply to Marslen-Wilson and Tyler. Cognition, 12, 109-117.

Dixon, W. J. (1985). BMDP statistical software. Berkeley: University of California Press.

Donchin, E., Coles, M. G. H. (1988). Is the P300 component a manifestation of context updating? Behavioral \& Brain Sciences, 11 , $357-428$

Donchin, E., Gerbrandt, L. K., Lejfer, L., \& Tucker, L. R. (1972). Is the contingent negative variation contingent on a motor response? Psychophysiology, 9, 178-188.

Drewnowski, A., \& Healy, A. F. (1977). Detection errors on "the" and "and": Evidence for reading units larger than the word. Memory \& Cognition, 5, 636-647.
Fischler, I, \& RANey, G. E. (in press). Language by eye: Behavioral. autonomic and cortical approaches to reading. In J. R. Jennings \& M. G. H. Coles (Eds.), Handbook of cognitive psychology: Central and autonomic nervous system approaches. New York: Wiley.

FLoRES D'ARCAIS, G. B. (1985). Children's recognition of function words. In G. A. J. Hoppebrouwers, P. A. M. Seuren, \& A. J. M. M. Weijters (Eds.) Meaning and the lexicon (pp. 124-131). Dordrecht, The Netherlands: Foris Publications Holland.

Forster, K. I. (1981). Priming and the effects of sentence and lexical contexts on naming time: Evidence for autonomous lexical processing. Quarterly Journal of Experimental Psychology, 33A, 465-495.

Foss, D. J. (1982). A discourse on semantic priming. Cognitive Psychology, 14, 590-607.

Francis, W. N., KUČERA, H. (1982). Frequency analysis of English usage: Lexicon and grammar. Boston: Houghton Mifflin.

FRIEDERICI, A. D. (1985). Levels of processing and vocabulary types: Evidence from on-line comprehension in normals and agrammatics Cognition, 19, 133-166.

Friederici, A. D., \& SChoenle, P. W. (1980). Computational distinction of two vocabulary types: Evidence from aphasia. Neuropsychologia, 18, 11-20.

Friedman, D., Simson, R., Ritter, W., \& Rapin, I. (1975). The late positive component (P300) and information processing in sentences. Electroencephalography \& Clinical Neurophysiology, 38, 255-262.

GARNSEY, S. M. (1985). Function words and content words: Reaction time and evoked potential measures of word recognition (Cognitive Science Tech. Rep. No. URCS-29). Rochester, NY: University of Rochester.

Garrett, M. (1978). Word and sentence perception. In R. Held, H. W. Leibowitz, \& H.-L. Teuber (Eds), Handbook of sensory physiology: Vol. VIII. Perception (pp. 611-626). Berlin: Springer-Verlag.

Goodman, G. C., McClelland, J. L., Gibbs, R. W. (1981). The role of syntactic context in word recognition. Memory \& Cognition, 9, 580-586.

Gordon, B., Caramazza, M. (1982). Lexical decision for openand closed-class words: Failure to replicate differential frequency sensitivity. Brain \& Language, 19, 335-345.

Gough, P. B. (1983). Context, form, and interaction. In K. Rayner (Ed.), Eye movements in reading: Perceptual and language processes (pp. 203-211). New York: Academic Press.

HABer, R. N., SCHINDler, R. M. (1981). Error in proofreading: Evidence of syntactic control of letter processing. Journal of Experimental Psychology: Human Perception \& Performance, 7. 573-579.

Hillyard, S. A. (1973). The CNV and human behavior: A review. Electroencephalography \& Clinical Neurophysiology Supplement, 33, 161-171.

Hillyard, S. A., KUTAS, M. (1983). Electrophysiology of cognitive processing. Annual Review of Psychology, 34, 33-61.

Hillyard, S. A., \& PICTON, T. W. (1987). Electrophysiology of cognition. In F. Plum (Ed.), Handbook of physiology: Sec. 1 . The nervous system: Vol. S. Higher functions of the brain (Part 2, pp. 519584). Bethesda, MD: American Physiological Society.

Hillyard, S. A., Woldorff, M., Mangun, G. R., \& Hansen, J. C. (1987). Mechanisms of early selective attention in auditory and visual modalities. Electroencephalography \& Clinical Neurophysiology, Suppl. 39. 317-324.

HoLcoмв, P. J. (1985). Unimodal and multimodal models of lexical memory: An ERP analysis. Psychophysiology, 22, 576. (Abstract)

IrWIN, D. A., KNott, J. R., MCAdaM, D. W., Rebert, C. S. (1966). Motivational determinants of the "contingent negative variation." Electroencephalography \& Clinical Neurophysiology, 21, 538-543.

JAKOBSON, R. (1956). Two aspects of language in two types of aphasic disturbances. In R. Jakobson \& M. Halle (Eds.), Fundamentals of language (Pp. 71-75). The Hague: Mouton.

JoHNSON, R., JR. (1988). The amplitude of the P300 component of the event-related potential: Review and synthesis. In P. K. Ackles, J. R. Jennings, \& M. G. H. Coles (Eds.), Advances in Psychophysiology (Vol. 3, pp. 69-138). Greenwich, CT: JAI Press.

Karniski, W., Vanderploeg, R. D., Diehl, S., Lease, L. (1988). 
Analysis of the $\mathbf{N} 400$ event-related potential component in a simple auditory sentence processing task. Psychophysiology, 25, 460-461. (Abstract)

KEPPEL, G. (1982). Design and analysis: A researcher's handbook. Englewood Cliffs, NJ: Prentice Hall.

Kolk, H. H. J., \& BlomerT, L. (1985). On the Bradley hypothesis concerning agrammatism: The nonword interference effect. Brain \& Language, 26, 94-105.

KUTAS, M. (1988). Review of event-related potential studies of memory. In M. S. Gazzaniga (Ed.), Perspectives in memory research (pp. 181-218). Cambridge, MA: MIT Press.

Kutas, M., Hillyard, S. A. (1980a). Event-related brain potentials to semantically inappropriate and surprisingly large words. Biological Psychology, 11, 99-116.

Kutas, M., Hillyard, S. A. (1980b). Reading between the lines: Event-related brain potentials during natural sentence processing. Brain \& Language, 11, 354-373.

Kutas, M., \& Hillyard, S. A. (1980c). Reading senseless sentences: Brain potentials reflect semantic incongruity. Science, 207, 203-205.

Kutas, M., Hillyard, S. A. (1982). The lateral distribution of eventrelated potentials during sentence processing. Neuropsychologia, 20 , 579-590.

KutAS, M., Hillyard, S. A. (1983). Event-related brain potentials to grammatical errors and semantic anomalies. Memory \& Cognilion, 11, 539-550.

Kutas, M., Hillyard, S. A. (1984). Brain potentials during reading reflect word expectancy and semantic association. Nature, $\mathbf{3 0 7}$, 161-163.

Kutas, M., Hillyard, S. A., \& Gazzaniga, M. S. (1988). Processing of semantic anomaly by right and left hemispheres of commissurotomy patients: Evidence from event-related brain potentials. Brain, 111, 553-576.

Kutas, M., Lindamood, T, \& Hillyard, S. A. (1984). Word expectancy and event-related brain potentials during sentence processing. In S. Kornblum \& J. Requin (Eds.), Preparatory states and processes (pp. 217-238). Hillsdale, NJ: Erlbaum.

Kutas, M., Neville, H. J., \& Holcomb, P. J. (1987). A preliminary comparison of the $\mathrm{N} 400$ response to semantic anomalies during reading, listening, and signing. Electroencephalography \& Clinical Neurophysiology, Suppl. 39, 325-330.

Kutas, M., \& VAN PetTen, C. (1988). Event-related brain potential studies of language. In P. K. Ackles, J. R. Jennings, \& M. G. H. Coles (Eds.), Advances in psychophysiology (Vol. 3, pp. 139-187). Greenwich, CT: JAI Press.

Kutas, M., Van Petten, C., \& Besson, M. (1988). Event-related potential asymmetries during the reading of sentences. Electroencephalography \& Clinical Neurophysiology, 69, 218-233.

Lukatela, G., Kostic, A., Feldman, L. B., \& Turvey, M. T. (1983) Grammatical priming of inflected nouns. Memory \& Cognition, 11 59-63.

lukatela, G., Moraca, J., Stojnov, D., Savic, M., Katz, L., \& TuRVEY, M. T. (1982). Grammatical priming effects between pronouns and inflected verb forms. Psychological Research, 44 297-311.

Mangun, G. R., Hillyard, S. A. (1990). Electrophysiological studies of visual selective attention in humans. In A. Scheibel \& A. Wechsler (Eds.), The neurobiological foundations of higher cognitive function (pp. 271-295). New York: Guilford

Marin, O. S. M., Saffran, E. M., \& Schwartz, M. F. (1976). Dissociations of language in aphasia: Implications for normal functions Annals of the New York Academy of Sciences, 280, 868-884.

MARSLEN-WiLSON, W., \& TYLER, L. K. (1980). The temporal structure of spoken language understanding. Cognition, 8, 1-71.

MCAdam, D. W., IrWin, D. A., Rebert, C. S., \& KNOTT, J. R. (1966). Conative control of the contingent negative variation. Electroencephalography \& Clinical Neurophysiology, 21, 194-195.

McCallum, W. C. (1988). Potentials related to expectancy, preparation and motor activity. In T. W. Picton (Ed.), Human event-related potentials: Handbook of electroencephalography and clinical neurophysiology (rev. ed., Vol. 3, pp. 427-534). Amsterdam: Elsevier.
McCallum, W. C., Cooper, R., Pocock, P. V. (1988). Brain slow potential and ERP changes associated with operator load in a visual tracking task. Electroencephalography \& Clinical Neurophysiology, 69, $453-468$

McCallum, W. C., Farmer, S. F., \& Pocock, P. K. (1984). The effects of physical and semantic incongruities on auditory event-related potentials. Electroencephalography \& Clinical Neurophysiology, 59, 477-488.

McCallum, W. C., \& Papakostopoulos, D. (1973). The CNV and reaction time in situations of increasing complexity. Electroencephalography \& Clinical Neurophysiology Supplement, Suppi. 33, 179-185.

MCCARThY, G., \& WoOd, C. C. (1985). Scalp distributions of eventrelated potentials: An ambiguity associated with analysis of variance models. Electroencephalography \& Clinical Neurophysiology: Evoked Potentials, 62, 203-208

MILLER, G. A., \& ISARD, S. (1963). Some perceptual consequences of linguistic rules. Joumal of Verbal Learning \& Verbal Behavior, 2, 217-228.

NevilLe, H. (1985). Biological constraints on semantic processing: A comparison of spoken and signed languages. Psychophysiology, 22, 576. (Abstract)

NeviLLE, H. J. (in press). Neurobiology of cognitive and language processing: Effects of early experience. In K. Gibson \& A. C. Petersen (Eds.), Brain maturation and cognitive development: Comparative and cross-cultural perspectives. Hawthorne, NY: Aldine Gruyter Press.

Neville, H. J., Kutas, M. Chesney, G., SChmidt, A. L. (1986). Event-related potentials during initial encoding and recognition memory of congruous and incongruous words. Journal of Memory \& Language, 25, 75-92

Neville, H. J., KUtas, M., SChmidt, A. (1982). Event-related potential studies of cerebral specialization during reading: 1 . Studies of normal adults. Brain \& Language, 16, 300-315.

O'REGAN, J. K. (1979). Saccade size control in reading: Evidence for the linguistic control hypothesis. Perception \& Psychophysics, 25, $501-509$

O'SeAGHdha, P. (1989). The dependence of lexical relatedness effects on syntactic connectedness. Journal of Experimental Psychology: Learning, Memory, \& Cognition, 15, 73-87.

Petocz, A., \& Oluphant, G. (1988). Closed-class words as first syllables do interfere with lexical decisions for nonwords: Implications for theories of agrammatism. Brain \& Language, 34, 127-146.

Pirch, J. H., Corbus, M. J. , Rigdon, G. C., \& LrNess, W. H. (1986). Generation of cortical event-related potentials in the rat involves nucleus basalis cholinergic innervation. Electroencephalography \& Clinical Neurophysiology. 63, 464-475.

Rohrbaugh, J. W., \& Galllard, A. W. K. (1983). Sensory and motor aspects of the contingent negative variation. In $A$. W. K. Gaillard \& W. Ritter (Eds,), Tutorials in event related potential research: Endogenous components (pp. 269-310). Amsterdam: North-Holland.

Rosenterg, B., Zurif, E., Brownell, H., Garrett, M., \& BradLEY, D. (1985). Grammatical class effects in relation to normal and aphasic sentence processing. Brain \& Language, 26, 287-303.

RUGG, M. D. (1985). The effects of semantic priming and word repetition on event-related potentials. Psychophysiology, 22, 642-647.

RugG, M. D., Furda, J, Lorist, M. (1988). The effects of task on the modulation of event-related potentials by word repetition. Psychophysiology, 25, 55-63.

RugG, M. D., \& NAGY, M. E. (1987). Lexical contribution to nonword repetition effects: Evidence from event-related potentials. Memory \& Cognition, 15, 473-481.

Segui, J., Mehler, J., Frauenfleder, W., \& Morton, J. (1982). The word frequency effect and lexical access. Neuropsychologia, 20 , 615-627

Seidenberg, M. S., Waters, G. S., Sanders, M., Langer, P. (1984). Pre- and postlexical loci of contextual effects on word recognition. Memory \& Cognition, 12, 315-328.

Sharkey, A. J. C., \& Sharkey, N. E. (1989). Lexical processing and the mechanism of context effects in text comprehension. Program of the Eleventh Annual Conference of the Cognitive Science Society, Ann Arbor, Michigan (pp. 466-473). Hillsdale, NJ: Erlbaum 
Simpson, G. B., Peterson, R. R., Casteel, M. A., \&urgess, C. (1989). Lexical and sentence context effects in word recognition. Journal of Experimental Psychology: Leaming, Memory, \& Cognition, $15,88-97$.

SMith, M. E., \& HaLGREN, E. (1987). Event-related potentials during lexical decision: Effects of repetition, word frequency, pronounceability, and concreteness. Electroencephalography \& Clinical Neurophysiology Supplement, 40, 417-421.

Smith-Burke, M., \& Gingrich, P. S. (1979). The differential role of function words and lexical items in narrative and expository text. In M. Kamil \& A. J. Moe (Eds.), Reading research: Studies and applications (pp. 45-48). Clemson, SC: National Reading Conference.

TYLER, L. K., \& MARSLEN-WILSON, W. (1986). The effects of context on the recognition of polymorphemic words. Journal of Memory \& Language, 25, 741-752.

TYLER, L. K., \& WARREN, P. (1987). Local and global structure in spoken language comprehension. Journal of Memory \& Language, 26, 638-657.

TYLER, L. K., WESSELS, J. (1983). Quantifying contextual contributions to word-recognition processes. Perception \& Psychophysics, 34, 409-420.

Van Petten, C. (1989). Context effects in word recognition: Studies using event-related brain potentials. Unpublished doctoral dissertation, University of California, San Diego.

VAN Petten, C., \& KUTAS, M. (1990a). Interactions between sentence context and word frequency in event-related brain potentials. Memory \& Cognition, 18, 380-393.

Van Petten, C., \& Kutas, M. (1990b). Two ERP components index word frequency and repetition during silent reading. Psychophysiology, 27, S6. (Abstract)

VASEY, W. V., THAYER, J. F. (1987). The continuing problem of false positives in repeated measures ANOVA in psychophysiology: A multivariate solution. Psychophysiology, 24, 479-486.

VERLEGER, R. (1988). Event-related potentials and cognition: A critique of the context updating hypothesis and an alternative interpretation of P3. Behavioral \& Brain Sciences, 11, 343-428.

Walter, W. G., Cooper, R., Aldridge, V. J., McCallum, W. C., \& WINTER, A. L. (1964). Contingent negative variation: An electric sign of sensorimotor association and expectancy in the human brain. Nature, 203, 380-384.

WANG, M.D. (1970). Influence of linguistic structure on comprehensibility and recognition. Journal of Experimental Psychology, 85, 83-89.

West, R. F., \& Stanovich, K. E. (1986). Robust effects of syntactic structure on visual word processing. Memory \& Cognition, 14, 104-112.

Wright, B., \& GarRetT, M. (1984). Lexical decision in sentences: Effects of syntactic structure. Memory \& Cognition, 12, 31-45.

ZURIF, E. (1980). Language mechanisms: A neuropsychological perspective. American Scientist, 68, 305-311.

\section{NOTES}

1. Care was taken to replace transitive verbs with other transitive verbs, and intransitive with intransitive. In addition, only "ly" adverbs were replaced; quantifiers such as "some" and "many" were not (see Cowart, 1982). Our dichotomous assignment of words to the open or closed class followed a similar principle of assigning words of ambiguous class to the closed-class category.

2. Sentence-initial open-class words were almost exclusively proper names, which were excluded from all analyses.

3. While a subject was being run, his/her EEG was digitized at a rate of 250 samples per second or one point every $4 \mathrm{msec}$. With our software, this sampling rate would ordinarily yield an epoch of $1.024 \mathrm{sec}$ (256 data points per epoch). To obtain the longer epoch of $5.120 \mathrm{sec}$, the sampling rate had to be reduced to 50 data points per second. One method of accomplishing this would be to select every fifth data point of the digitized EEG before averaging the single trials. Rather than discard four fifths of the original data in this manner, we employed an interpolation technique wherein each data point of the reduced-samplingrate EEG was an average of points in that time region of the original higher-sampling-rate EEG. In the final ERP average, a single data point thus represents $20 \mathrm{msec}$ of brain activity, but the time resolution is somewhat better than would be expected from a sampling rate of $50 \mathrm{~Hz}$.

4. A running average or "boxcar" filter of 1 sec was used to compute the slow activity. This activity was then subtracted from the original EEG to leave the higher frequencies.

5. Figure 5 displays data that was not subjected to the digital highpass filter applied to intermediate word data. The purpose of the filter was to remove slow activity that occurred across the course of entire sentences, extending from the ERP epoch of one word on into the baseline for the epoch of the next word. In the case of final words, the purity of the baseline for subsequent words is not a concern; leaving the data unfiltered allowed us to observe low-frequency activity late in the epoch.

6 . One might be concerned that the mean amplitude measure used to quantify the $\mathrm{N} 400$ would be contaminated by the positive wave seen later in the epoch in the case of final words. However, analyses using a peak amplitude measure (most negative point in 200 - to 500 -msec latency window) yielded similar results.

7. In the present results, it is also possible that there was some temporal overlap between the $\mathrm{N} 400$ and late positivity elicited by syntactic final words. Given the larger amplitude of the $\mathrm{N} 400$ at right hemisphere sites, it would have tended to cancel out some of the right hemisphere P300 and reduce the apparent asymmetry of this component.

8. The pattern of scalp distribution shown by the late positivity can be modeled by a quadratic trend (U-shaped curve) in the anterior-posterior dimension). The quadratic component of trend was significant for all three sentence types [congruent, $F(1,37)=92.7$; syntactic, $F(1,37)=$ 52.9; random, $F(1,37)=21.0$; all $p s<.0001]$ and accounted for $80 \%$ to $84 \%$ of the variance in the anterior-posterior dimension in each sentence type (see Keppel, 1982, p. 441). Each pairwise comparison between the sentence types yielded significant interactions between sentence type and the quadratic component because the anterior-posterior scalp distribution was quite symmetric around the parietal maximum for the random sentences but was skewed toward the front of the head for the syntactic sentences and toward the back of the head for congruent sentences.

9. More recently, Rohrbaugh and Gaillard (1983) have argued that there is little evidence for a "true CNV." Rather, the negative potential is simply a conjunction of two components, neither of which is specific to the pairing of two stimuli: an "orienting response" to the first stimulus followed by preparation to make a motor response to the second stimulus. In the present case, as in others, a frontal negativity was observed in the absence of any motor requirement (Donchin, Gerbrandt, Leifer, \& Tucker, 1972). Their second argument, that the nonmotor part of the CNV is determined by the characteristics of the first stimulus alone, rather than by its association with a subsequent stimulus, is not meaningful when the stimuli are words in text. Since closedclass words are infrequently used to terminate sentences, one of their fundamental characteristics is to signal an upcoming word.

10. As an illustration, consider the following hypothetical pattern of results: Effect $\mathrm{A}$ is $4 \mu \mathrm{V}$ at Electrode 1 and $2 \mu \mathrm{V}$ at Electrode 2; Effect $\mathrm{B}$ is $2 \mu \mathrm{V}$ at Electrode 1 and $1 \mu \mathrm{V}$ at Electrode 2. Thus, both effects have the same scalp distribution of being twice as large at Electrode 1 as at Electrode 2, but Effect $A$ is twice as large at each site. Despite the identical scalp distribution, this situation might yield a significant effect $X$ electrode interaction in an ANOVA because the difference between the two effects was $2 \mu \mathrm{V}$ at Electrode 1 and only $1 \mu \mathrm{V}$ at Electrode 2 .

(Manuscript received August 1989; revision accepted for publication June 20, 1990.) 